\title{
Wood Stove Use in the End-Use Load and Consumer Assessment Program Residential Base Sample
}

\author{
B. A. LeBaron
}

November 1988

Prepared for the

Bonneville Power Administration

under a Related Services Agreement

with the U.S. Department of Energy

Contract DE-AC06-76RLO 1830

Pacific Northwest Laboratory

Operated for the U.S. Department of Energy

by Battelle Memorial Institute 


\title{
DISCLAIMER
}

This report was prepared as an account of work sponsored by an agency of the United States Government. Neither the United States Government nor any agency thereof, nor Battelle Memorial Institute, nor any or their employees, makes any warranty, expressed or implied, or assumes any legal liability or responsibility for the accuracy, completeness, or usefulness of any information, apparatus, product, or process disclosed, or represents that its use would not infringe privately owned rights. Reference herein to any specific commercial product, process, or service by trade name, trademark, manufacturer, or otherwise does not necessarily constitute or imply its endorsement, recommendation, or favoring by the United States Government or any agency thereof, or Battelle Memorial Institute. The views and opinions of authors expressed herein do not necessarily state or reflect those of the United States Government or any agency thereof.

\author{
PACIFIC NORTHWEST LABORATORY \\ operated by \\ BATTELLE MEMORIAL INSTITUTE \\ for the \\ UNITED STATES DEPARTMENT OF ENERGY \\ under Contract DE-AC06-76RLO 1830
}

Printed in the United States of America
Available from
National Technical Information Service
United States Department of Commerce
5285 Port Royal Road
Springfield, Virginia 22161
NTIS Price Codes
Microfiche A01
Printed Copy
Pages
$001-025$
$026-050$


PNL -6713

UC-95c

WOOD STOVE USE IN THE END-USE LOAD AND CONSUMER ASSESSMENT PROGRAM

RESIDENTIAL BASE SAMPLE

B. A. LeBaron

November 1988

Prepared for the Bonneville Power Administration under a Related Services Agreement with the U.S. Department of Energy Contract DE-AC06-76RLO 1830

Pacific Northwest Laboratory Richland, Washington 99352 
. : 


\section{EXECUTIVE SUMMARY}

This report examines wood heating in the End-Use Load and Consumer Assessment Program (ELCAP) Residential Base Sample during the 1985/1986 heating season. The goals of this study were to assess the frequency of wood burning in homes having wood burning equipment and to estimate the quantity of electrical space heat displaced by its use.

In the ELCAP Residential Base Sample, $43 \%$ of the residences had the capability for major wood heating (wood stoves) and an additional $28 \%$ had minor wood heating capabilities (fireplaces). However, only $24 \%$ of the total sample actually used wood burning equipment as their primary heat source. Throughout this report, the term wood stove will be used to describe both wood stove and fireplace equipment. The use of wood for wood burning is examined from August 18, 1985, through May 31, 1986 (287 days); this time period is defined as the heating season. Not all sites had data for the entire study period; consequently, only the 68 sites that had at least $50 \%$ of the possible data were used. This restriction minimizes the chance of seasonat bias.

Wood stove operation and electrical space heating were monitored at each site by a microprocessor-controlled data logger. This allowed precise knowledge of electrical consumption and frequency of wood stove use over short periods of time. For each site, the days are partitioned into two groups: days when wood burning equipment was used and days when it was not. Days containing missing data are not included. This classification permits examination of seasonal patterns of use and comparisons between wood-use and nonwood-use electrical space heating loads.

Patterns of wood stove usage were investigated on both a seasonal level and a daily level. The results permit several main conclusions about the usage of wood stoves in the ELCAP Residential Base sample:

- More than half the households that have wood stoves use them for space heating throughout the heating season. There are, however, wood households in the sample that never use their wood. 
- During the coldest months, the frequency of wood use is strongly bimodal, with large groups either burning wood almost every day or quite rarely, and with relatively few homes at intermediate levels of wood-use frequency.

- Diurnal profiles of wood use aggregated across a reasonable number of sites are qualitatively similar to those for other forms of heat and, in particular, for electrical space heat. The principal difference for wood heat is that evening use is larger than morning use; the converse is generally true for electric heat.

- The dispersion in usage behavior across the sample of sites studied is quite large for all hours of the day.

Quantifying the affect of wood use on residential space heating is very. important to therma] performance analysis. An investigation of the amount of electrical space heating displaced by wood use was made for both individual sites and for the sample as a whole. The results of this examination can be summarized as follows:

- The envelope performance analysis used to assess conservation performance in the Residential Standards Demonstration Program is strongly affected by wood stove use. Daily duration of wood burning is directly related to the amount of electrical space heating displaced.

- Daily electrical heating load shapes show an overall reduction throughout the heating season for days when there is wood heating. In particular, maximum displacement occurs during the morning and evening hours reflecting the periods when wood burning is heaviest.

- The two-parameter regression employed to model heating displacement for individual structures provides site-specific estimates but can only be applied to the light to moderate wood users. Thus, this method's resulting sample mean savings estimate of $1502 \mathrm{kWh} / \mathrm{year}$ for the 1985/1986 heating season is correspondingly low.

- Monthly and annual estimates of electrical space heating displacement derived by differencing aggregate load profiles for wood use 
and nonwood use provide reasonable sample values. Homes that burned wood in this study displaced an average of $1951 \mathrm{kWh}$ of electrical space heating during the 1985/1986 heating season. 



\section{CONTENTS}

EXECUTIVE SUMMARY $\ldots \ldots \ldots \ldots \ldots \ldots \ldots$

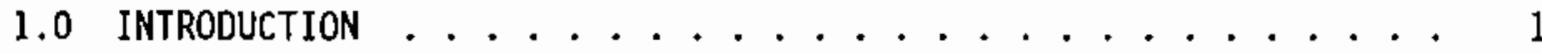

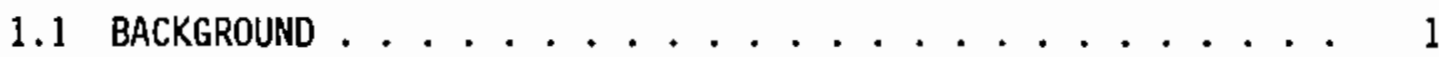

1.2 END-USE LOAD AND CONSUMER ASSESSMENT PROGRAM . . . . . 2

2.0 Site SElection. . . . . . . . . . . . . . 5

3.0 MEASUREMENT .......................... 7

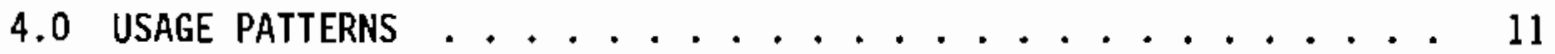

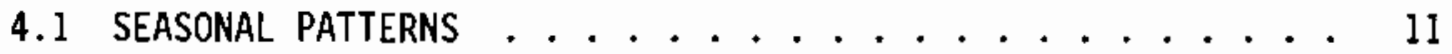

4.2 DAILY PATTERNS . . . . . . . . . . . . . . 15

4.3 CONCLUSIONS . . . . . . . . . . . . . . . 19

5.0 DISPLACEMENT OF ELECTRICAL SPACE HEAT . . . . . . . . 21

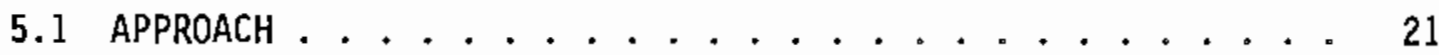

5.2 SINGLE-STRUCTURE DISPLACEMENT . . . . . . . . 21

5.3 EFFECTS ON LOAD SHAPE . . . . . . . . . . . 26

5.4 SAMPLE DISPLACEMENT $\ldots \ldots \ldots \ldots$

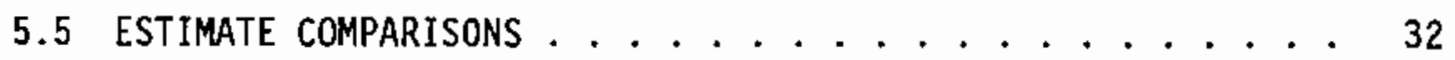

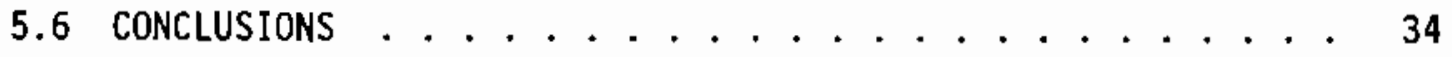

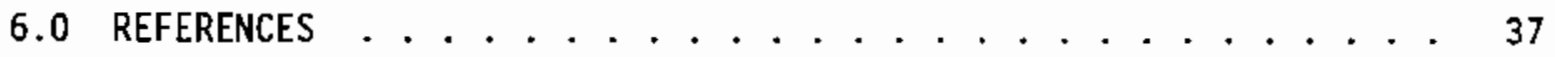

APPENDIX A - DISTRIBUTION OF DATA ............... A.I 


\section{FIGURES}

1 Distribution of ELCAP Residential Base Sample Sites for

Primary Heating Devices............... 3

2 Distribution of the Wood Burning Study Sites by Type of Wood Burning Device................ 6

3 Nine Days of Typical Time Series Data from a Thermocouple Hood Stove Sensor............... 7

4 Typical Time Series Data for August 1, 1985, to May 31, 1986, from a Thermocouple Wood Stove Sensor . . . . . . . . . . 8

5 Sorted Frequency of Wood Use for 68 Sites Over the Period from August 18, 1985, Through May 31, 1986 ......... 12

6 Frequency Distribution of Wood Use for 68 Sites . . . . . . 12

7 Evolution Over Time of the Frequency Distribution of of Wood Heat Use ................ 13

8 Bimodal Nature of the Frequency Distribution of Wood Use December to February .............. 14

9 Mean Percent Wood Use by Month ............... 14

10 Box Plots Showing the Range in Frequency of Wood Use for Sites Located in Each of the Three NWPPC Climate Zones ....... 15

11 Weekday Distribution by Hour of Percent Wood Use for the 68 Sampled Sites ................ 17

12 Weekend Distribution by Hour of Percent Wood Use for the 68 sites .................... 17

13 Display of Weekday and Weekend Diurnal Patterns in Frequency of Wood Stove Use .............. 18

14 Relationship Between Frequency of Wood Burning Days and the Duration of Wood Burning During Those Days ....... 18

15 Relationship Between Outside Temperature and Space Heating Loads for Nonwood-Use (0) and Hood-Use $(\Delta)$ Days . . . . . . . 22

I6 Distribution of Estimated Annual Electrical Space Heating Displacement for 35 Wood Burning Homes ....... 26 
17 Mean Hourly Electrical Space Heating Load Profile for Nonwood-Use (0) and Wood-Use ( $\Delta$ ) Days from

September Through May ................... 27

18 Stacked Hourly Electrical Space Heating Displacements

from September through May ................ 28 


\section{TABLES}

1 Number of ELCAP Residential Base Sample Sites and Wood Stove

Sample Sites Located in NWPPC CT imate Zones . . . . . . . . . 5

2 Site-Specific Electrical Space Heating Displacement

for the Wood Stove Sites . . . . . . . . . . . . . 24

3 The Mean Seasonal Heating Load, Monthly Peak Heating Load, and Associated Load Factor ............ 29

4 Electrical Heating Values When No Wood Burning Occurred ... . 30

5 Electrical Heating Values when Wood Burning Was Used ..... 31

6 Electrical Space Heating Displaced by Hood Stove Use . . . . . 31

A.1 Number of Days When the Hood Stove Was Used .......... A.I

A.2 Number of Days When the Wood Stove Was Not Used . . . . . . A.3 


\section{INTRODUCTION}

\subsection{BACKGROUND}

Wood has been used as a residential heating fuel for thousands of years. Its popularity as a heating fuel in the United States has generally declined since the turn of the century because of the declining price and convenience of electricity and fossil fuels. However, since the mid-1970s, residential wood use has experienced a revival following the surge in conventional heating costs. It has been estimated that approximately 20 milijon households currently burn wood and, of these, about $30 \%$ use wood as their primary heating source (Skog and Watterson 1983).

The Pacific Northwest is no exception to this trend. Surveys have reported that as high as $62 \%$ of the homes in this region have the capability to heat with wood (Lane Regional Air Pollution Authority 1984). However, the number that use wood as a primary heating source is much less, approximately $21 \%$ (Tonn and White 1986). The percentage of homes that supplement their space heating with wood burning falls somewhere in between. For example, the Oregon Department of Energy's Residential Energy Conservation Survey (Oregon Department of Environmental Quality 1985) estimated that 58\% of Oregon's households burned some wood.

This widespread capacity for wood heating indicates that residential space heating in the Northwest is rapidly becoming an electric/wood market with the potential for large swings in the residential demand for electricity because of fuel switching (Tonn and white 1986). For example, if the cost of electricity should rise, more home owners will perceive wood heating to be less expensive and start to increase their use of wood heating. Or the opposite situation, declining electricity prices may result in decreased wood heating and a proportional rise in electrical demand.

The estimation of electrical displacement by residential wood heating in the United States has generally been approached through surveys of firewood cutting on public and private lands. While these data may be readily available, it can only indicate gross regional trends in wood consumption for residential heating. Subsequent efforts to equate the amount of wood burned 
to space heating energy displaced are complicated by the wide variation in the heating value of wood and stove combustion efficiency (Sheldon 1983; Modera and Sonderegger 1980; Modera 1985).

Other analyses have used electrical billing data in conjunction with participant surveys of wood use to determine electricity savings from wood space heating. The weakness here is that survey responses to estimated cords of wood consumed are unreliable. Respondent estimated wood usage may represent more of an indicator of the propensity to burn wood than the quantity actually burned (Fels and Stram 1986).

The Northwest Power Planning Council (NWPPC) currently assumes, for purposes of estimating the Pacific Northwest electrical resource needs, that homes built to current construction practice will, on the average, derive $10 \%$ of their auxiliary heat from wood stoves (NWPPC 1986). This is an average displacement across all homes, including those without wood stoves.

\subsection{END-USE LOAD AND CONSUMER ASSESSMENT PROGRAM}

The End-Use Load and Consumer Assessment Program (ELCAP) is operated by Pacific Northwest Laboratory (PNL) under the direction of the Bonneville Power Administration (BPA) for the purpose of improving electrical power load forecasting capabilities. This report summarizes the analysis of wood stove use in this program's Residential Base Sample homes. The goals of this study were to assess the frequency of wood burning in homes equipped with wood burning equipment (i.e., wood stoves and fireplaces) and to estimate the displacement of electrical space heating loads by wood heat.

In the ELCAP Residential Base Sample from which this study draws its sample, 24\% of the residences were heated primarily with wood (Figure 1). Forty-three percent had the capability for major wood heating (wood stoves), and an additional $28 \%$ had minor wood heating capabilities (fireplaces). Throughout the remainder of this report, the term wood stove will be used to define both wood stoves and fireplaces. These percentages were obtained from an onsite inspection as part of the Residential Buitding Characteristics Survey (BPA 1985). 


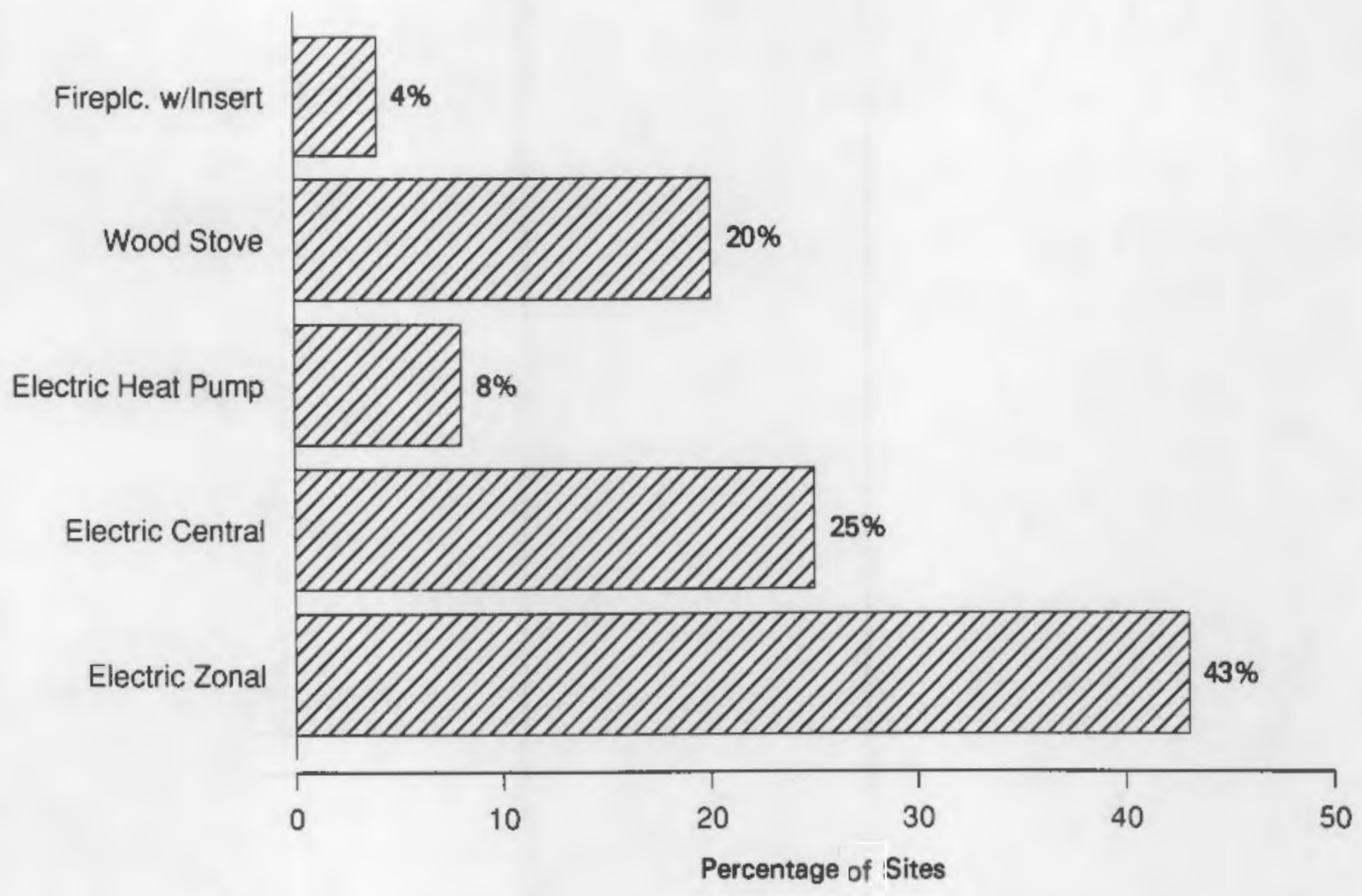

FIGURE 1. Distribution of ELCAP Residential Base Sample Sites for Primary Heating Devices

In the ELCAP study, electric end-use monitoring by a microprocessorcontrolled data logger (Schuster and Tomich 1985) allowed a precise knowledge of the electrical consumption of the heating system in each residence over short intervals of time. The same equipment also tracked the duration and frequency of wood burning. This report covers the analysis of the data from a large number of wood burning houses that provided some new insights into the role wood heating plays in residential energy use. Sections 2.0 and 3.0 discuss site-selection and the wood stove sensor. Sections 4.0 and 5.0 discuss the results and conclusions for usage patterns and displacement of electric space heating. 



\subsection{SITE SELECTION}

The wood stove study encompassed a data base of 98 sites taken from 184 ELCAP Residential Base Sample (Bonneville Power Administration 1985) sites having major wood burning capabilities. These sites were carefully selected from 143 sites equipped with wood burning sensors to be those providing reliable data for a reasonable fraction of the 1985/1986 heating season (Appendix A). Table 1 indicates that although only half of the possible sites were used, a proportional number were located in each of the NWPPCdefined (Hadley and Pincus 1985) climate zones. Climate Zone 1 is the mildest while $\mathrm{Cl}$ imate Zone 3 is the most severe.

Each site had one sensor monitoring a wood burning device. It was assumed that at sites having more than one heating device (both a wood stove and a fireplace) the sensor was installed in the chimney of the major wood heat source. Figure 2 shows the distribution of the sample by type of wood burning device (Bonneville Power Administration 1985). In this report, references to wood stove usage include the few fireplaces in the sample.

Frequency of wood stove use was examined from August 8, 1985, through May 31, 1986 (287 days). Not all sites have data for the entire period. Statistics on the usage across the full heating season were based on data from only the 68 sites having at least $50 \%$ of the possible data. This restriction minimizes the chance of biasing the results to a particular portion of the heating season.

TABLE 1. Number of ELCAP Residential Base Sample Sites and Wood Stove Sample Sites Located in the NWPPC Climate Zone

\begin{tabular}{cccc} 
Climate Zone & Base Sample & Study Sample \\
\cline { 1 - 2 } 1 & 101 & 52 \\
2 & 57 & 31 \\
3 & $\underline{26}$ & $\underline{15}$ \\
Total $^{184}$ & 98
\end{tabular}




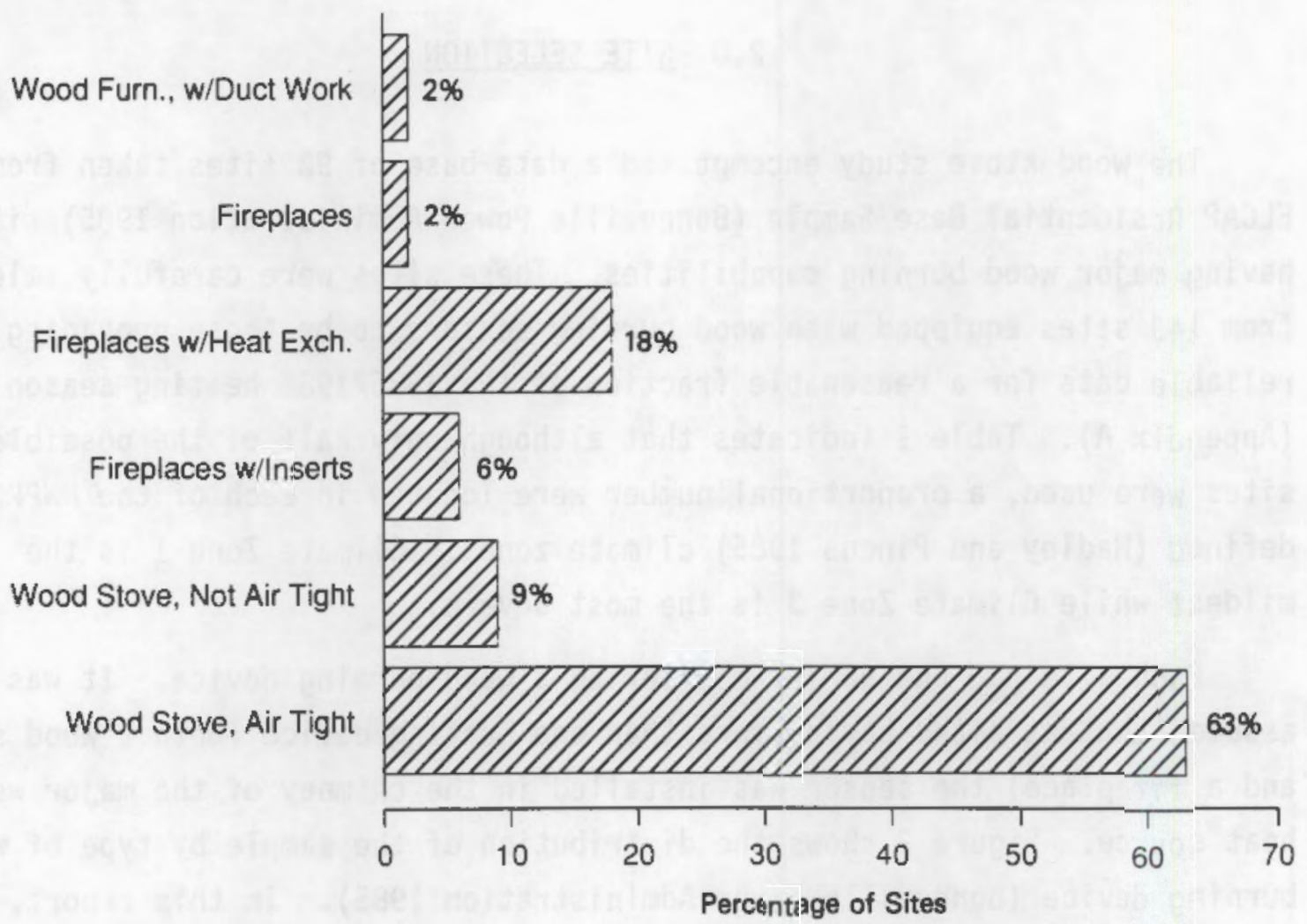

FIGURE 2. Distribution of the Wood Burning Study Sites by Type of Wood Burning Device 


\subsection{MEASUREMENT}

The sensor used to monitor wood stove use consisted of a thermocouple with a floating temperature reference junction. One junction of the thermocouple was positioned inside the chimney approximately $3 \mathrm{ft}$ from the top. The connection to these wires was made with copper wire outside the chimney. This created two more junctions in which temperatures following ambient conditions created a floating junction. Therefore, the output of the sensor was directly related to the difference between the temperature in the chimney and the temperature of the outside (ambient) air.

Nine days of typical time-series data from a wood stove sensor are given in Figure 3. The vertical lines represent midnight for each $24-h$ period. It is possible to identify periods of wood use because the magnitude of the signal generated when the wood burning-device was in use was much larger than the diurnal background signal variation. This background signal variation is the result of variation in the outside temperature. By carefully choosing a

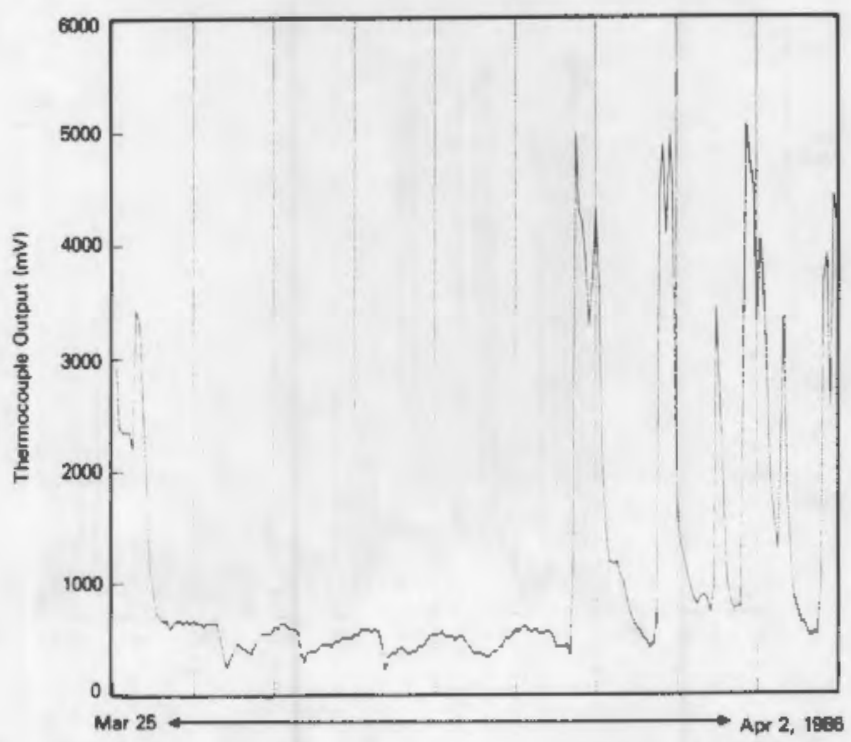

FIGURE 3. Nine Days of Typical Time Series Data from a Thermocouple Wood Stove Sensor 
threshold value just above the background variation, it is possible to distinguish between days when the wood stove was in use and days when it was not, indicating the frequency of wood use.

The procedure for determining the frequency of wood use is illustrated in Figure 4. This site exhibits only modest temperature dependence in the baseline signal. The maximum value of the background signal occurred around November 25, 1985 (the coldest part of the 1985/1986 heating season). The threshold value of the wood stove signal was set slightly higher than this maximum background signal. Note that at this threshold level, some wood-use days are not included, particularly in the warmer season when the background signal was low; for example, around May 4, 1986. Although the threshold process is not perfect in separating wood-use from nonwood-use days, there is only a modest contribution from the wood stove based on the low level of the signal on the few days that were missed by this procedure.

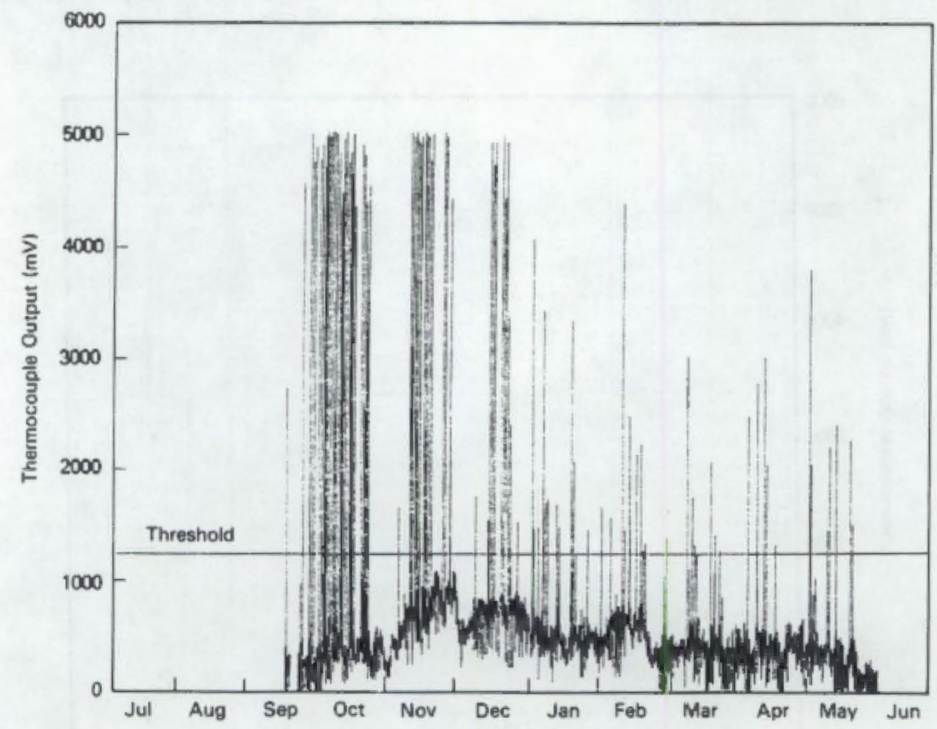

FIGURE 4. Typical Time Series Data for August 18, 1985, to May 31, 1986, May 31, 1986, from a Thermocouple Wood Stove Sensor 
For each sample site examined, a threshold was chosen and the days of the heating season partitioned into wood-use and nonwood-use days. Days were assigned to the wood-use category if for any hour of the day the sensor output was above the threshold value. Otherwise, days were assigned to the nonwood-use category. In this anatysis, a day was classified as missing even if $1 \mathrm{~h}$ of data was not recorded. 



\subsection{USAGE PATTERNS}

\subsection{SEASONAL PATTERNS}

This section describes the variation of wood stove usage throughout the heating season and classifies the results for each site into two groups: the days that wood burning equipment was used and the days that it was not. This classification permits examination of seasonal usage patterns but does not retain information about quantity of use.

Figure 5 shows the sorted distribution of frequency of use for 68 wood stove sites during the heating season; it also indicates the sample sites that used wood burning equipment every day and sites that did not use it at a11. Figure 6 summarizes these results in the form of a bar graph; data used to generate the figure are ratios of days on which wood stoves were used to days for which data are available. Judging by frequency of use, most sites appear to burn wood intensively, with 40 out of 68 burning wood at least $50 \%$ of the days.

Figure 7 shows the distribution, by month, of wood burning intensity, as measured by fraction of days, when wood was burned. For each month, sites with two-thirds or more of available data were included. The data show a gradual transition from infrequent to frequent use during the fall, a bimodal distribution during the coldest part of winter, and a return from intensive to occasional use during spring. The distribution during the cold months indicates that the sample divides into frequent wood users and occasional wood users; there are few intermediate cases. Figure 8 shows a combined distribution for the December to February period. This figure exhibits the strong bimodal nature of the distribution quite clearly.

A different view of these data is provided in Figure 9, where the mean percent of wood-use days is plotted by month. Again, the monthly means are taken for sites that have at least two-thirds of the data available for a particular month. The pattern shows a steady increase in wood usage from September through December, with a subsequent decline. The rate of change in frequency of wood use is large at the beginning and end of the heating 


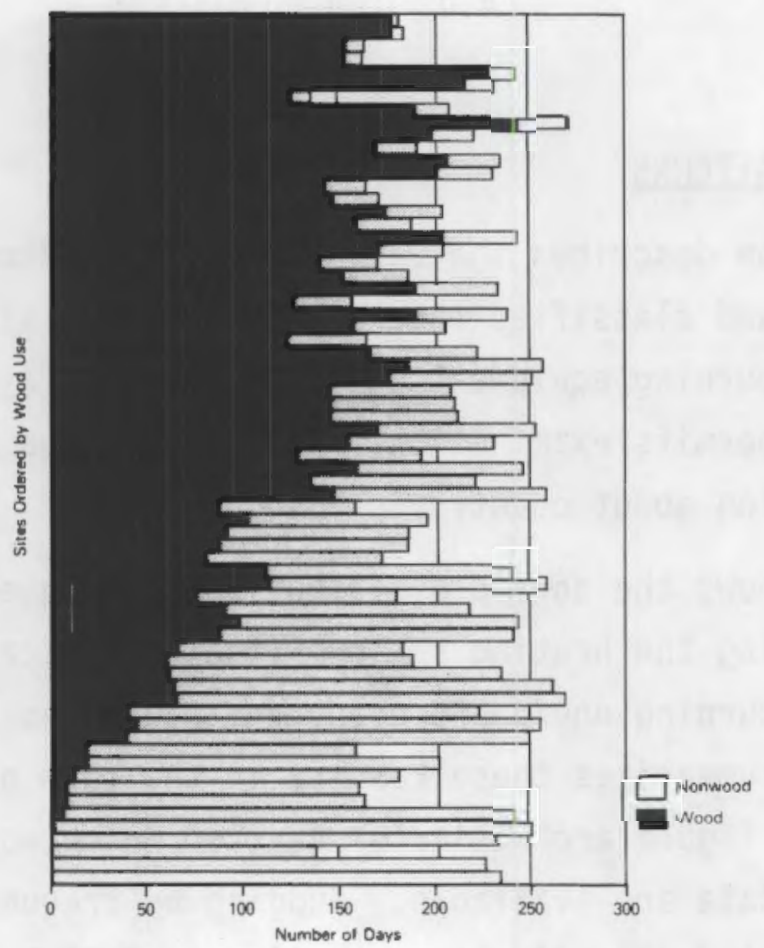

FIGURE 5. Sorted Frequency of Wood Use for 68 Sites Over the Period from August 18, 1985, Through May 31, 1986

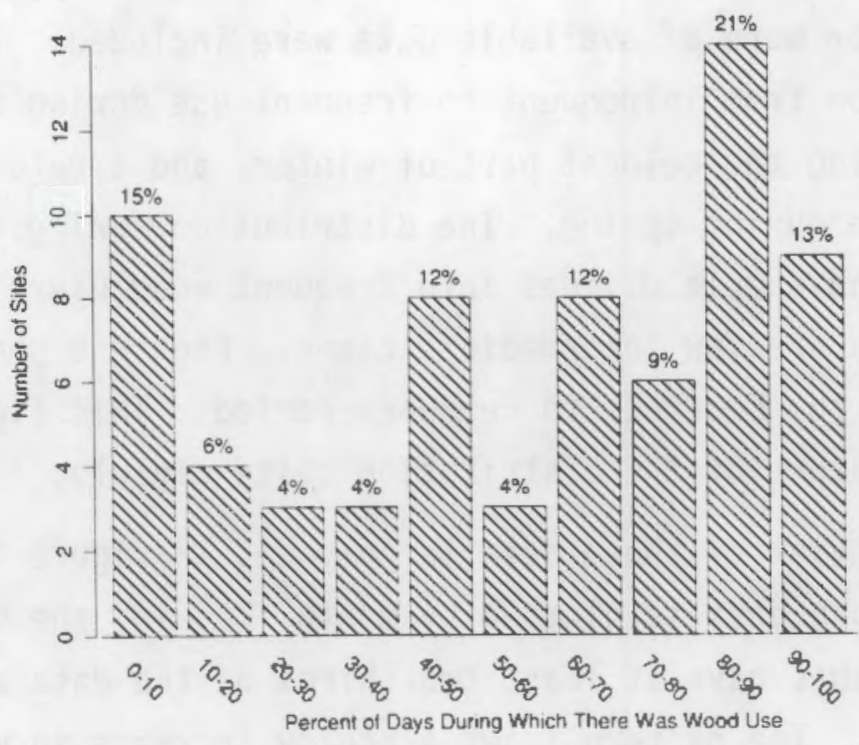

FIGURE 6. Frequency Distribution of Wood Use for 68 Sites 

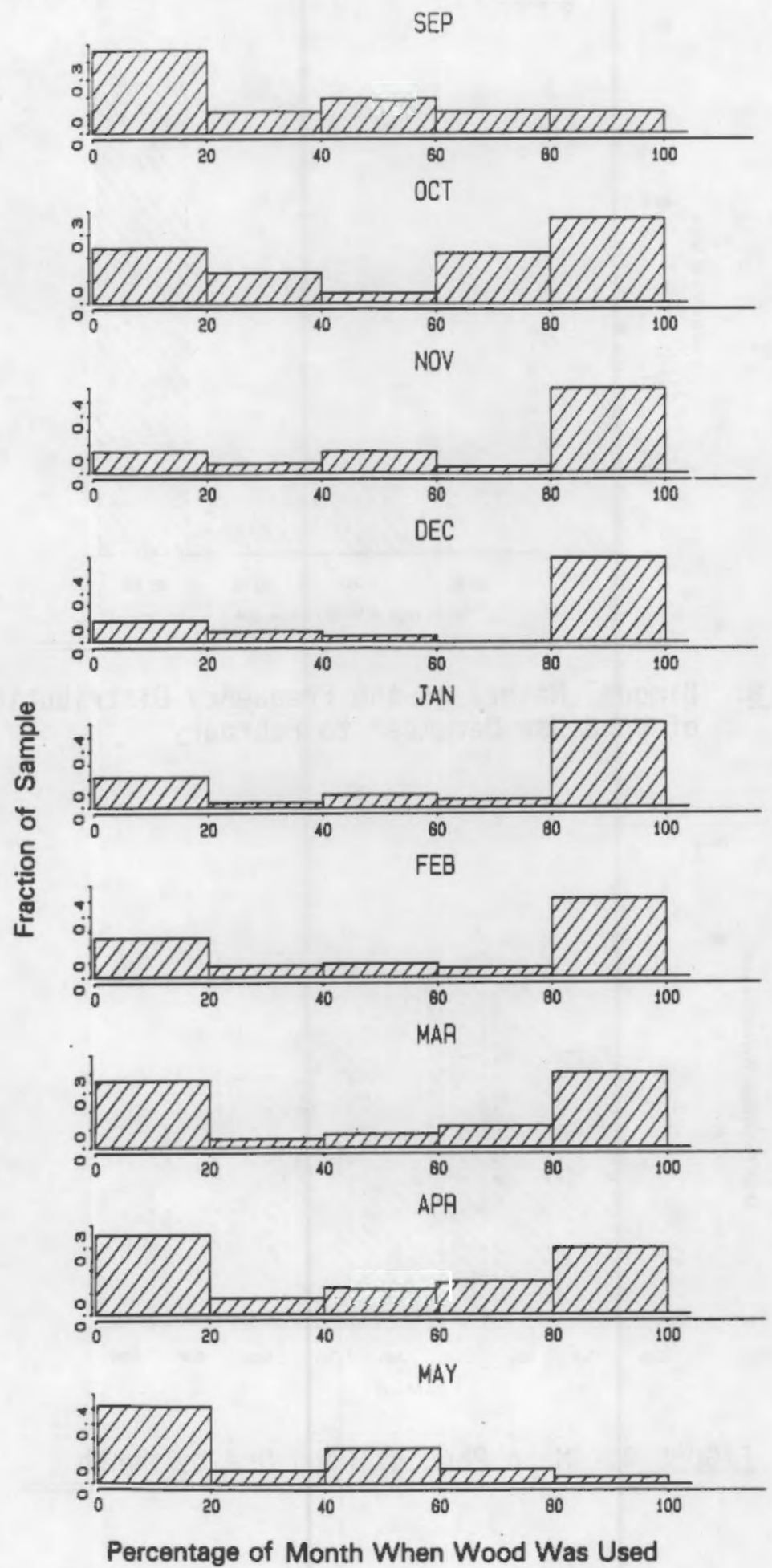

FIGURE 7. Evolution Over Time of the Frequency Distribution of Wood Heat Use 


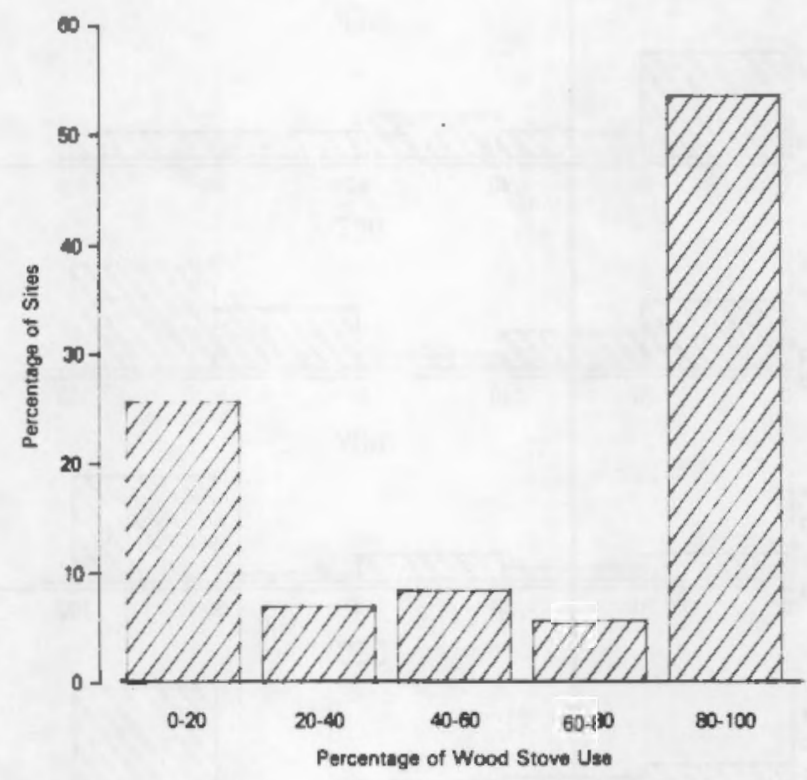

\section{FIGURE 8. Bimodal Nature of the Frequency Distribution of Wood Use December to February}

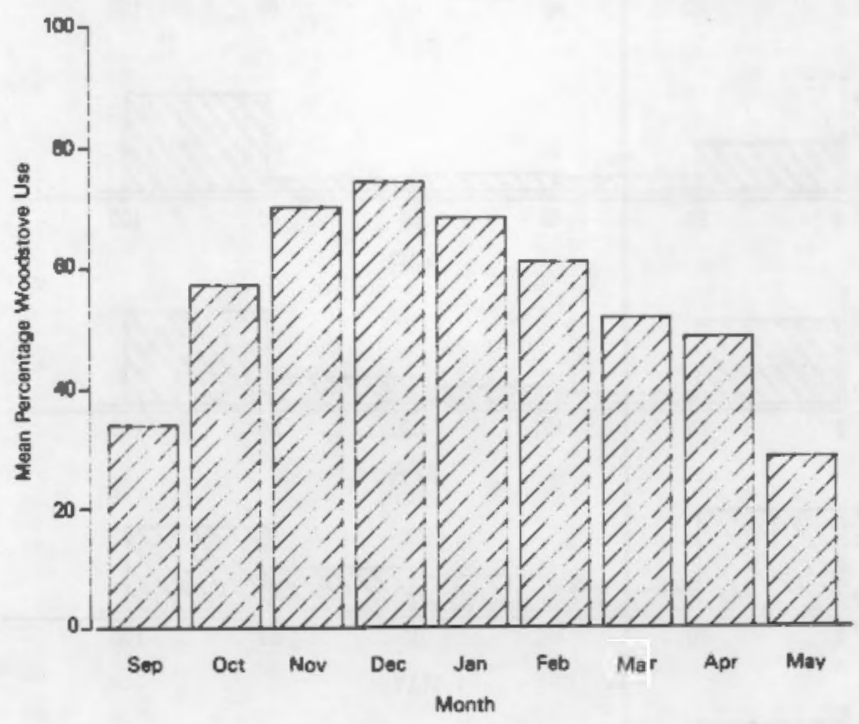

FIGURE 9. Mean Percent Wood Use by Month 
season, but was slow during the coldest months. It is possible that the high use in November was associated with the early arrival of cold weather in much of the region during the 1985 heating season.

The frequency of wood use does not appear to depend on the climate zone. Figure 10 shows box plots indicating the frequency-of-use distributions for the sample partitioned by the basis of the climate zones defined by the NWPPC (Hadley and Pincus 1985). Climate Zone 1 is the mildest and includes the bulk of single-family homes in the region, while $\mathrm{Cl}$ imate Zone 3 is the most severe. The box contains the interquartiles, the dividing line is the median, and the lines extending from the ends of the box approximate the range of the sites. This figure provides no basis for asserting a strong dependence of climatic location on the tendency to use wood.

\subsection{DAILY PATTERNS}

This section characterizes the hourly usage patterns for the wood stove sample of ELCAP homes, disaggregated by weekday and weekend. For the purpose

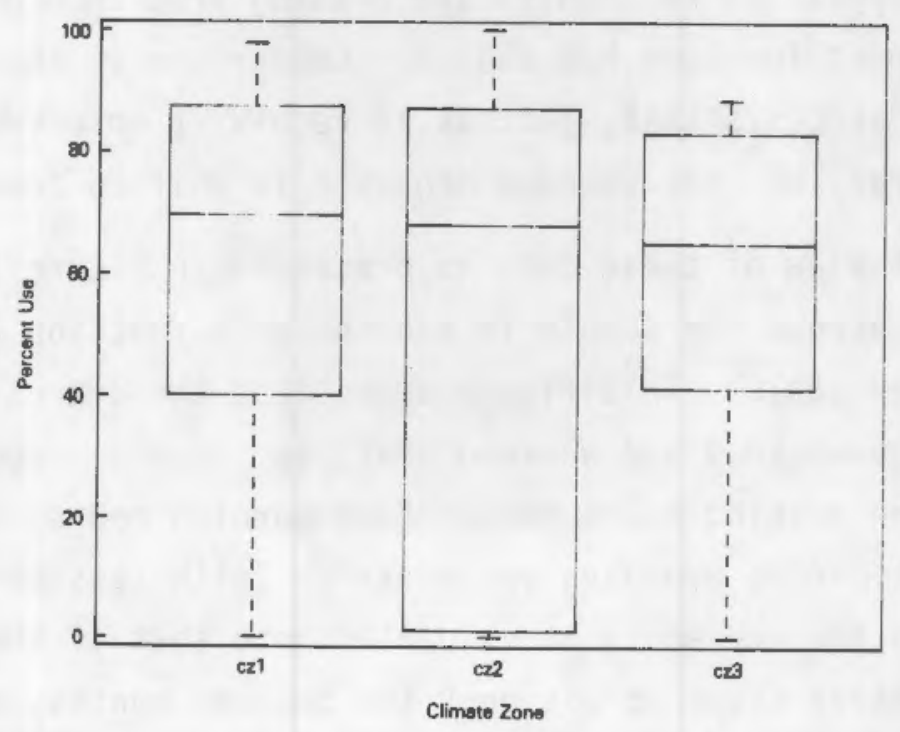

FIGURE 10. Box Plot Showing the Range in Frequency of Wood Use for Sites Located in Each of the Three NWPPC Climate Zones 
of this work, a wood stove is considered "on" for a full hour if the wood stove sensor gives a value above the on/off threshold, even though the stove may be cooling off. Percent-on time for each individual site serves as the basic data for this study, with each day's available data weighted equally.

Figures 11 and 12 provide box plot summaries of the weekday and weekend profiles, respectively. For each hour, the box plot summarizes the percenton time data through the heating season for the sites in the sample. The box contains the interquatiles, the dividing line is the median, and the lines extending from the ends of the box approximate the range of the sites.

Diurnal patterns are evident in both figures, with maxima at 7:00 to 9:00 am and 8:00 to $10: 00 \mathrm{pm}$. Roughly speaking, the data are reminiscent of typical load shapes for electric space heating, except that the relative magnitude of morning and evening peaks is reversed. That is, wood usage appears to be more intense in the evening than in the morning.

The spread in intensity of use, as measured by the interquartile range (shown on the figure as the height of the box), is substantial at all hours, and there does appear to be significant heating from wood even during the early morning hours for some households. Comparison of the weekday and weekend figures suggests that, just as is regularly observed in electrical space heating profiles, the weekend schedule is shifted toward later hours.

A different view of these data is presented in Figure 13, where mean percent-on time across the sample is plotted as a function of hour on a slightly expanded scale. This figure emphasizes the diurnal pattern and the comparison of the weekday and weekend profiles. Again, wood is burned more frequently during evening hours rather than morning hours, and the difference in burning times during weekdays and weekends (with less morning use and more afternoon use on the weekends) is evident. Note that if these figures had reflected wood stove usage across only the coldest months, mean usage would have been larger for all hours.

Figure 14 is a scatter plot showing the correlation of frequency of wood burning days to the duration of wood burning during those days. The ratio of the number of days that wood was used for heat to the total number of days available is plotted against the mean daily fraction of wood burning for each 


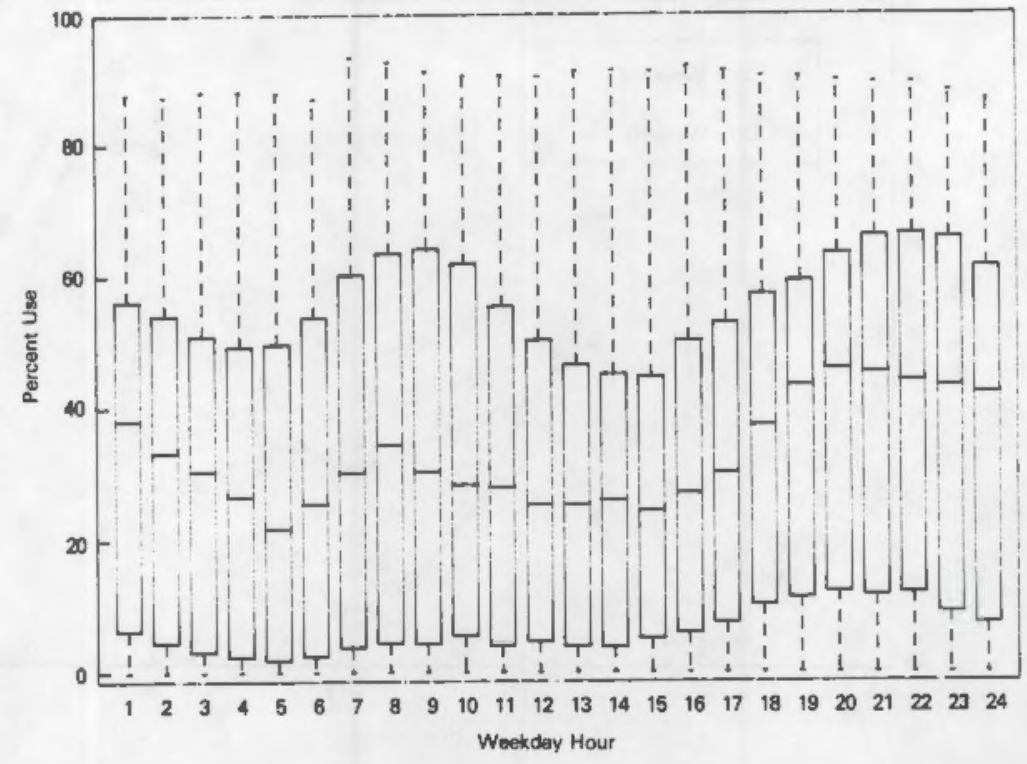

FIGURE 11. Weekday Distribution by Hour of Percent Wood Use for the 68 Sampled Sites

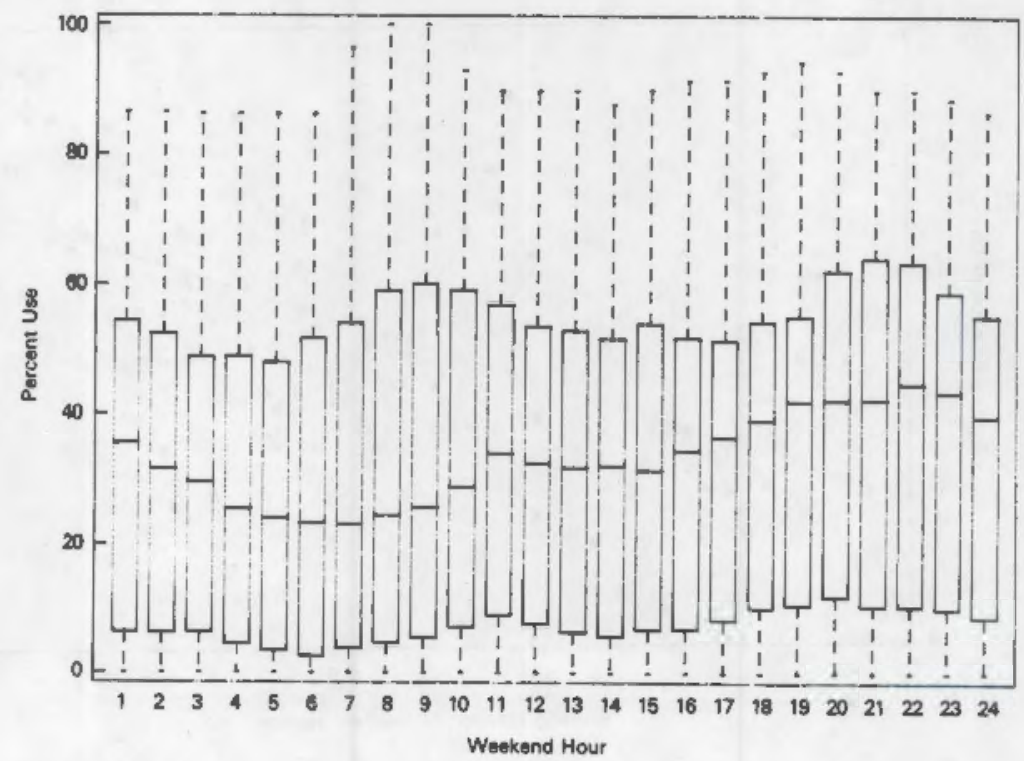

FIGURE 12. Weekday Distribution by Hour of Percent Wood Use for the 68 Sites

site. One would expect a relatively tight relationship; however, the figure shows a lot of scatter. A regression line drawn through the data points indicates a positive trend, although there is a large associated error. 


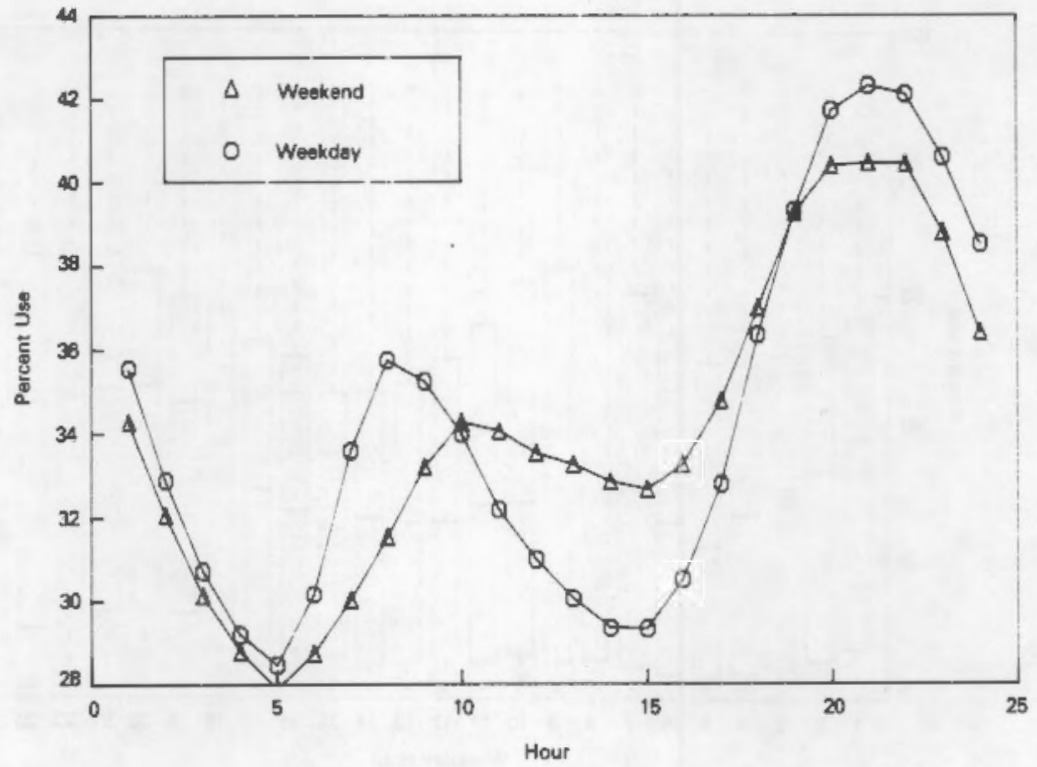

FIGURE 13. Display of Weekday and Weekend Diurnal Patterns in Frequency of Wood Stove Use

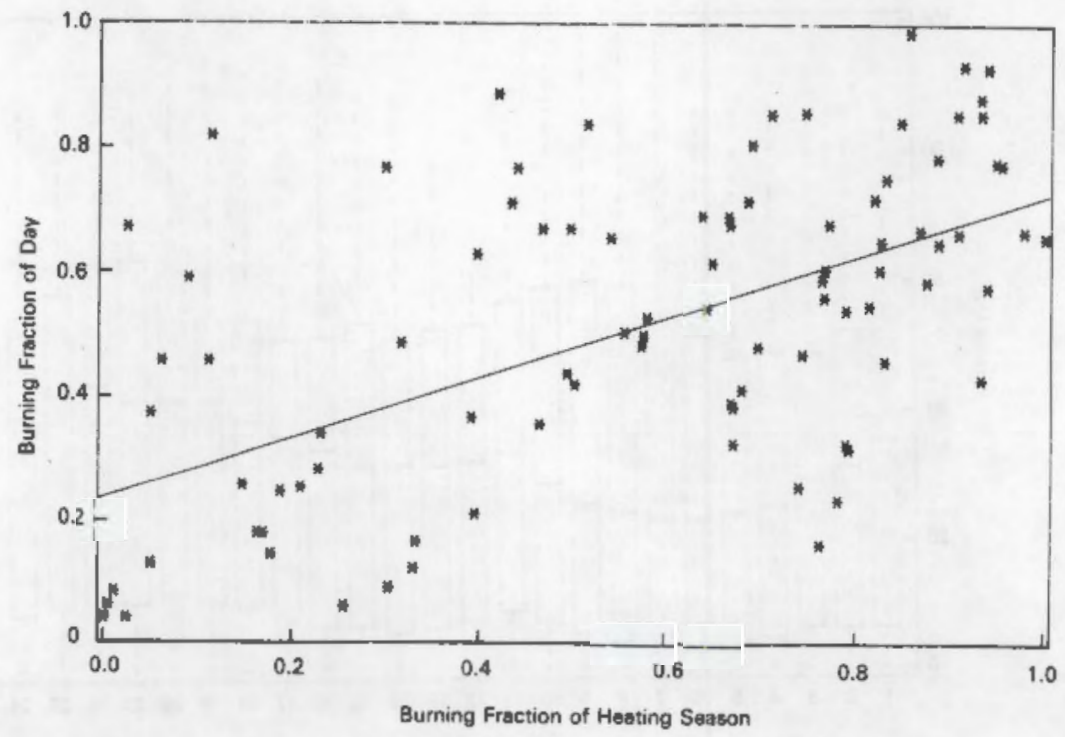

FIGURE 14. Relationship Between Frequency of Wood Burning Days and the Duration of Wood Burning During Those Days 
Occupants who burn wood on a large number of days during the heating season tend to also burn wood for a greater fraction of the hours during those days. The relationship is strongest for the heavy wood users; they are the occupants who use wood as their primary heat source and, therefore, burn it more frequently and for a larger fraction of the day.

\subsection{CONCLUSIONS}

The results of our investigations permit several observations about the seasonal usage of wood stoves in the random sample of the ELCAP Residential Base Sample participants:

- More than half the households that have wood stoves use them for space heating throughout the heating season. There are, however, wood sites in the sample that never use their wood stoves.

- The seasonal pattern in frequency of wood use across the sample shows a rapid increase at the beginning and a rapid decrease at the end of the heating season, with little variation over the coldest month. In these data, the peak in frequency comes in December.

- During the coldest months, the population of wood users is strongly bimodal with respect to frequency of wood heating. Households with wood stoves either heat with wood almost every day or quite rarely, with relatively few homes at intermediate levels of wood use frequency.

- These summary results suggest that, given that wood burning equipment is available, climatic region does not seem to be a strong determinant of frequency of use.

Analysis of daily patterns of wood stove usage can be summarized in the following:

- Diurnal profiles of wood use aggregated across a reasonable number of sites are qualitatively similar to those for other forms of heat and, in particular, for electrical space heat. The principal difference for wood heat is that evening use is more frequent than morning use; the converse is generally true for electric heat. 
Consequently (to the extent that wood users are qualitatively similar to nonwood users in their use of electrical space heat), it may be expected that wood use increases the ratio of morning residential peak in electric loads to an average load.

- The differences between weekday and weekend profiles of wood use intensity are similar to differences between weekday and weekend profiles for space heating and other electrical end-uses. That is, schedules are shifted somewhat later for weekends as opposed to weekdays, and there is more afternoon use on weekends.

- The variability in usage behavior across the sample studied here is quite large for all hours of the day.

- 0ccupants who burn wood frequently during the heating season tend (with a large associated error) to also burn wood for a greater fraction of the hours during those days. 


\subsection{DISPLACEMENT OF ELECTRICAL SPACE HEAT}

\subsection{APPROACH}

Probably the most important impact of wood heating on residential electricity use is the amount of electrical heating energy it displaces. Estimates of displacement in aggregate are important to the understanding of the absolute effects of wood burning on the power demand. Site-specific displacement estimates are the first step in developing correlations with structure characteristics data.

Utilities are also interested in the effects of wood heating on daily load demands. If wood use tends to occur during the hours of peak demand (typically early morning) its potential as a load reduction measure is greatly increased. A simple indicator of power grid efficiency can be defined as the ratio of peak load to mean load (referred to as the load factor). Ideally, power utilities would like to supply electricity to a grid such that this ratio has a value close to unity, indicating efficient use of generating and transmission resources at all times. Because this is seldom the case, an examination of wood heating effects on hourly load profiles is important to future planning.

In this section, the annual electrical heating displacement for both the individual structure and the study in aggregate is estimated. Two techniques, a regression model and a load shape model, are employed. These techniques provide two independent estimates that can then be compared. Additional comparisons are made with displacement estimates reported by other investigators.

\subsection{SINGLE-STRUCTURE OISPLACEMENT}

The dramatic impact wood burning has on electrical space heating can be observed by plotting daily electrical heating load versus outside air temperature for a wood burning residence. This impact is illustrated in Figure 15 where the dots (0) show electrical space heating consumption for homes that did not burn wood, and the triangles $(\Delta)$ represent the same for homes that did burn. This plot is similar to those plots used in the 


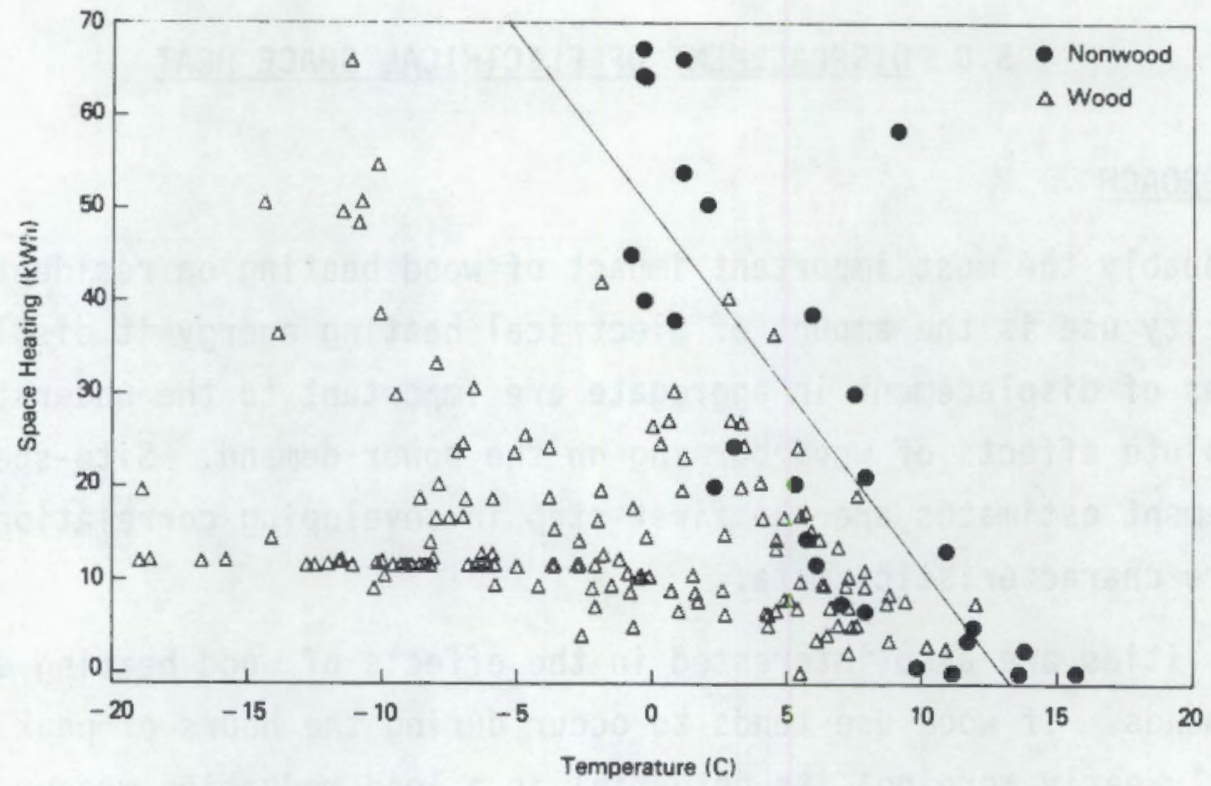

FIGURE 15. Relationship Between Outside Temperature and Space Heating Loads for Nonwood-Use (0) and Wood-Use $(\Delta)$ Days

envelope performance analysis for assessing the value of conservation measures in the Residential Standards Demonstration Program (RSDP) (Stokes and Pearson 1985). The outside air temperature was used rather than the inside/ outside temperature difference, because the inside temperature in a woodheated home may rise well above the thermostat setting. This would yield a temperature difference that would predict an erroneously high energy savings.

The line in Figure 15 represents a least-squares fit to the days when no wood heating occurred (points marked with dots). It is clear by the way the wood heating days fall below this line, that wood stove use displaces electrical space heating requirements. The magnitude of this displacement is dependent on the fraction of the day the wood stove was used.

A model similar to that used to calculate the thermal efficiency of homes in the ELCAP RSDP study was developed for examining site-specific electrical space heating displacement. A daily fractional wood use term was added to account for wood stove effects. The result is a two-parameter regression model represented by the following equation:

$$
Q h=a+b(O A T)-c(W S V)
$$


The electrical space heating energy required, Qh, is obtained from the daily mean hourly heating load. Outside air temperature (OAT) is taken from the daily mean outside air temperature. The daily fractional wood use (WSV) is calculated from the ratio of the number of hours of burning to $24 \mathrm{~h}$ in a day; $a, b$, and $c$ are the coefficients of the regression. The third coefficient, c, multiplied by the daily fractional use can be considered the wood stove contribution to the homes internal gains; this can also be equated to the electrical space heating displaced by wood stove use.

Analysis was made of a11 98 sites in the sample regardless of their available wood stove data. The site number, total number of days of available wood stove data, number of wood-use days, mean fractional wood use on wood-use days, correlation statistics, and mean hourly electrical displacement on wood use days are listed in Table 2. Results were obtained for only 76 of the 98 sites since 11 sites did not use wood during the number of days available for analysis and an additional 11 sites lacked either the electrical space heating or outside air temperature information necessary for the regression. Many of the sites had too few number of days to be representative of the entire 287-day heating season. In addition, many of the sites had poor correlation statistics $(t< \pm 2)$ indicating that the coefficients are not significant. Figure 16 is a bar graph of the estimated annual electrical space heating savings for the 35 sites that had significant coefficients and at least 100 days of data (this represents a compromise between reducing seasonal bias and retaining enough sites for meaningful analysis) or $35 \%$ of available data. The 35 sites have a mean displacement of $14 \mathrm{kWh}$ per wood use day and a mean annual displacement of $1502 \mathrm{kWh}$, based on electrical heating and wood stove usage in the 1985/1986 heating season.

It was found that the two-parameter regression used to predict sitespecific displacement gives statistically insignificant results for heavy wood-use sites. This is because the electrical heating for these sites is displaced to such an extent that a statistically meaningful correlation is not possible. Hence, the estimate of mean annual savings based on this method will be biased to the light and moderate wood stove users and will underestimate the wood stove savings for the total study. 
TABLE 2. Site-Specific Electrical Space Heating Displacement for the Wood Stove Sites

\begin{tabular}{|c|c|c|c|c|c|c|c|c|}
\hline \multirow[b]{2}{*}{ Count } & \multirow{2}{*}{$\begin{array}{l}\text { Site } \\
\text { Number }\end{array}$} & \multirow{2}{*}{$\begin{array}{l}\text { Total } \\
\text { Days }\end{array}$} & \multirow{2}{*}{$\begin{array}{l}\text { Wood } \\
\text { Days }\end{array}$} & \multirow{2}{*}{$\begin{array}{c}\text { Fraction } \\
\text { of Use } \\
\end{array}$} & \multicolumn{3}{|c|}{$\begin{array}{c}\text { Correlation } \\
\text { Statistic }\end{array}$} & \multirow{2}{*}{$\begin{array}{l}\text { Displace- } \\
\text { ment (Wh) }\end{array}$} \\
\hline & & & & & $\mathrm{Tl}$ & $\mathrm{T} 2$ & T3 & \\
\hline 1 & 30 & 141 & 137 & 0.953 & 7.53 & -7.62 & -2.20 & 7 \\
\hline 2 & 31 & 122 & 114 & 0.860 & 5.73 & -5.61 & -3.94 & 1171 \\
\hline 3 & 33 & 61 & 44 & 0.577 & 0.17 & -0.02 & 1.49 & $\begin{array}{r}11 / 1 \\
-8\end{array}$ \\
\hline 4 & 50 & 106 & 1 & 0.125 & 18.56 & -17.73 & $\begin{array}{r}1.47 \\
-0.45\end{array}$ & 224 \\
\hline 5 & 61 & 143 & 143 & 0.605 & 9.21 & -9.56 & -1.58 & 11 \\
\hline 6 & 66 & 244 & 202 & 0.609 & -5.02 & 5.28 & 1.00 & -32 \\
\hline 7 & 69 & 210 & 146 & 0.695 & 3.43 & -3.31 & -3.94 & 385 \\
\hline 8 & 72 & 153 & 15 & 0.508 & 6.94 & -6.65 & 0.44 & -52 \\
\hline 9 & 85 & 144 & 80 & 0.520 & 12.45 & -11.82 & -9.07 & 515 \\
\hline 10 & 125 & 95 & 65 & 0.752 & 18.53 & -17.75 & -11.52 & 1709 \\
\hline 11 & 129 & 63 & 48 & 0.497 & 0.85 & -0.79 & -1.21 & 48 \\
\hline 12 & 134 & 142 & 45 & 0.428 & 10.99 & -10.31 & -4.23 & 444 \\
\hline 13 & 136 & 212 & 176 & 0.655 & 6.08 & -5.97 & -5.31 & 376 \\
\hline 14 & 138 & 154 & 64 & 0.893 & 23.14 & -22.04 & -20.78 & 1834 \\
\hline 15 & 144 & 153 & 144 & 0.836 & 1.99 & -1.92 & -2.42 & 12 \\
\hline 16 & 147 & 228 & 139 & 0.751 & 10.65 & -10.30 & -18.49 & 1315 \\
\hline 17 & 163 & 65 & 44 & 0.702 & 6.86 & -6.75 & 0.51 & -31 \\
\hline 18 & 165 & 243 & 168 & 0.817 & 21.39 & -21.15 & -7.66 & 588 \\
\hline 19 & 177 & 232 & 115 & 0.718 & 13.76 & -13.31 & -18.77 & 1536 \\
\hline 20 & 203 & 155 & 126 & 0.757 & 14.32 & -13.87 & -12.23 & 954 \\
\hline 21 & 204 & 82 & 63 & 0.436 & 2.13 & -2.11 & 1.14 & -39 \\
\hline 22 & 211 & 247 & 59 & 0.355 & 23.93 & -23.14 & -8.67 & 619 \\
\hline 23 & 216 & 252 & 64 & 0.286 & 25.93 & -25.21 & -4.40 & 310 \\
\hline 24 & 224 & 218 & 177 & 0.578 & 8.24 & -8.04 & -4.76 & 212 \\
\hline 25 & 227 & 76 & 31 & 0.792 & 8.75 & -8.58 & -4.30 & 405 \\
\hline 26 & 237 & 91 & 15 & 0.183 & 15.52 & -15.08 & -1.53 & 10 \\
\hline 27 & 243 & 196 & 138 & 0.390 & 5.82 & -5.52 & 1.18 & -53 \\
\hline 28 & 245 & 200 & 90 & 0.369 & 10.94 & -10.73 & -3.45 & 86 \\
\hline 29 & 246 & 178 & 146 & 0.557 & 3.73 & -3.79 & 4.77 & -614 \\
\hline 30 & 249 & 196 & 164 & 0.760 & 12.08 & -11.61 & -1.70 & 214 \\
\hline 31 & 256 & 30 & 10 & 0.096 & 1.83 & -1.74 & -0.47 & 55 \\
\hline 32 & 259 & 171 & 100 & 0.870 & 7.74 & -7.49 & -7.44 & 3022 \\
\hline 33 & 261 & 251 & 238 & 0.695 & 3.32 & -3.34 & -0.88 & 2 \\
\hline 34 & 262 & 129 & & 0.153 & -1.72 & 1.97 & 0.93 & -176 \\
\hline 35 & 271 & 167 & 156 & 0.843 & 3.16 & -2.79 & -6.50 & 252 \\
\hline 36 & 276 & 175 & 124 & 0.475 & -2.97 & 3.04 & 1.63 & -76 \\
\hline 37 & 317 & 134 & 128 & 0.693 & 9.56 & -9.47 & -2.00 & 176 \\
\hline 38 & 343 & 93 & 48 & 0.543 & 8.15 & -7.82 & -1.04 & 248 \\
\hline
\end{tabular}


TABLE 2. (contd)

\begin{tabular}{|c|c|c|c|c|c|c|c|c|}
\hline \multirow[b]{2}{*}{ Count } & \multirow{2}{*}{$\begin{array}{l}\text { Site } \\
\text { Number }\end{array}$} & \multirow{2}{*}{$\begin{array}{l}\text { Total } \\
\text { Days }\end{array}$} & \multirow{2}{*}{$\begin{array}{l}\text { Wood } \\
\text { Days }\end{array}$} & \multirow{2}{*}{$\begin{array}{l}\text { Fraction } \\
\text { of Use } \\
\end{array}$} & \multicolumn{3}{|c|}{$\begin{array}{l}\text { Correlation } \\
\text { Statistic }\end{array}$} & \multirow{2}{*}{$\begin{array}{l}\text { Displace- } \\
\text { ment (Wh) }\end{array}$} \\
\hline & & & & & $\mathrm{TI}$ & $\mathrm{T} 2$ & T3 & \\
\hline 39 & 347 & 195 & 65 & 0.171 & 0.35 & -0.28 & -0.87 & 4 \\
\hline 40 & 350 & 193 & 6 & 0.778 & 39.09 & -37.37 & 1.27 & -557 \\
\hline 41 & 352 & 209 & 38 & 0.148 & 28.49 & -27.52 & -5.68 & 639 \\
\hline 42 & 357 & 98 & 89 & 0.663 & 10.93 & -10.36 & -4.82 & 475 \\
\hline 43 & 363 & 224 & 164 & 0.729 & 3.60 & -3.56 & -0.65 & 17 \\
\hline 44 & 369 & 176 & 154 & 0.661 & 13.25 & -12.70 & -15.11 & 1300 \\
\hline 45 & 371 & 169 & 165 & 0.683 & 4.38 & -4.16 & -5.09 & 289 \\
\hline 46 & 374 & 163 & 115 & 0.862 & 21.23 & -20.83 & -4.96 & 669 \\
\hline 47 & 376 & 221 & 96 & 0.213 & 4.72 & -4.06 & -1.68 & 21 \\
\hline 48 & 379 & 181 & 166 & 0.906 & 15.03 & -15.13 & -2.62 & 265 \\
\hline 49 & 380 & 203 & 163 & 0.870 & 10.90 & -10.90 & -3.38 & 139 \\
\hline 50 & 382 & 13 & 13 & 0.231 & -- & -. & - & - \\
\hline 51 & 384 & 209 & 40 & 0.191 & 32.91 & -31.79 & -7.70 & 487 \\
\hline 52 & 392 & 209 & 141 & 0.653 & 6.56 & -6.25 & -2.52 & 155 \\
\hline 53 & 399 & 175 & 147 & 0.615 & 10.61 & -10.23 & -9.77 & 972 \\
\hline 54 & 400 & 125 & 44 & 0.063 & 24.94 & -23.11 & 1.30 & -118 \\
\hline 55 & 406 & 188 & 145 & 0.666 & 15.82 & -15.48 & -4.27 & 404 \\
\hline 56 & 418 & 82 & 73 & 0.303 & 12.14 & -11.89 & -5.39 & 443 \\
\hline 57 & 425 & 79 & 18 & 0.442 & 5.10 & -4.96 & -2.62 & 137 \\
\hline 58 & 429 & 231 & 136 & 0.337 & 11.14 & -10.92 & 3.48 & -146 \\
\hline 59 & 433 & 80 & 13 & 0.737 & 1.93 & -1.89 & -0.68 & 36 \\
\hline 60 & 434 & 125 & 15 & 0.261 & 15.14 & -14.41 & -3.09 & 919 \\
\hline 61 & 436 & 189 & 60 & 0.496 & 19.70 & -19.19 & -1.68 & 224 \\
\hline 62 & 438 & 109 & 104 & 0.782 & 6.71 & -6.63 & 1.00 & -78 \\
\hline 63 & 461 & 162 & 10 & 0.463 & 15.69 & -15.24 & -0.34 & 68 \\
\hline 64 & 462 & 210 & 74 & 0.130 & 26.78 & -25.43 & -6.40 & 296 \\
\hline 65 & 463 & 214 & 180 & 0.344 & 2.75 & -1.93 & 3.99 & -145 \\
\hline 66 & 468 & 80 & 59 & 0.270 & 3.84 & -3.80 & -0.98 & 54 \\
\hline 67 & 469 & 158 & 87 & 0.446 & 9.13 & -8.83 & -0.53 & 56 \\
\hline 68 & 473 & 200 & 143 & 0.334 & 20.38 & -19.75 & -7.05 & 502 \\
\hline 69 & 490 & 76 & 61 & 0.324 & 11.35 & -11.11 & -4.88 & 372 \\
\hline 70 & 491 & 203 & 18 & 0.623 & 2.62 & -2.51 & -1.40 & 37 \\
\hline 71 & 493 & 53 & 20 & 0.623 & 8.03 & -7.87 & -7.93 & 1658 \\
\hline 72 & 496 & 73 & 20 & 0.260 & 9.58 & -9.30 & -1.12 & 77 \\
\hline 73 & 507 & 163 & 140 & 0.994 & 8.34 & -8.35 & -2.21 & 126 \\
\hline 74 & 512 & 26 & 3 & 0.597 & 8.15 & -7.87 & -6.64 & 718 \\
\hline 75 & 51 & 98 & 7 & 0.833 & 20.26 & -19.72 & -3.89 & 1441 \\
\hline 76 & 514 & 139 & 110 & 0.521 & 14.23 & -14.03 & -4.55 & 332 \\
\hline
\end{tabular}




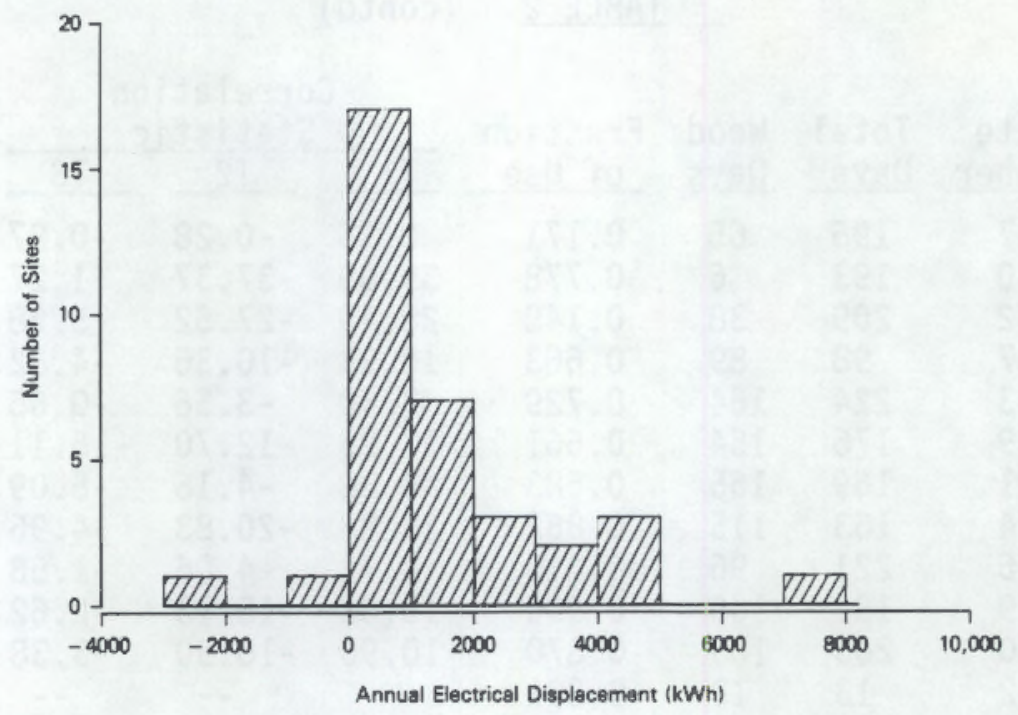

FIGURE 16. Distribution of Estimated Annual Electrical Space Heating Displacement for 35 Wood Burning Homes

\subsection{EFFECTS ON LOAD SHAPE}

This subsection examines the effects of wood burning on hourly load demands. A sample of 68 wood burning homes with enough data to be representative $(50 \%)$ of the entire heating season were used. Hourly electrical heating values were grouped as to wood-use or nonwood-use days for each month (September through May) for each site. The data from each group was then folded into a single day and the mean taken across sites. The result was a mean wood-use day and a mean nonwood-use day for each month.

Figure 17 contains the resulting monthly plots of hourly electrical heating load for the 68 sites. The curve marked with circles represents the hourly load when there was no wood burning. The second curve, marked with triangles, is the corresponding wood burning hourly load profile. Because of the method of binning, data for a site typically appears as a component of both curves.

Not surprisingly, the load profiles generally increase from fall to midwinter and then decrease. The wood burning profiles in each month fall below those for nonwood burning indicating the level of electrical displacement. 


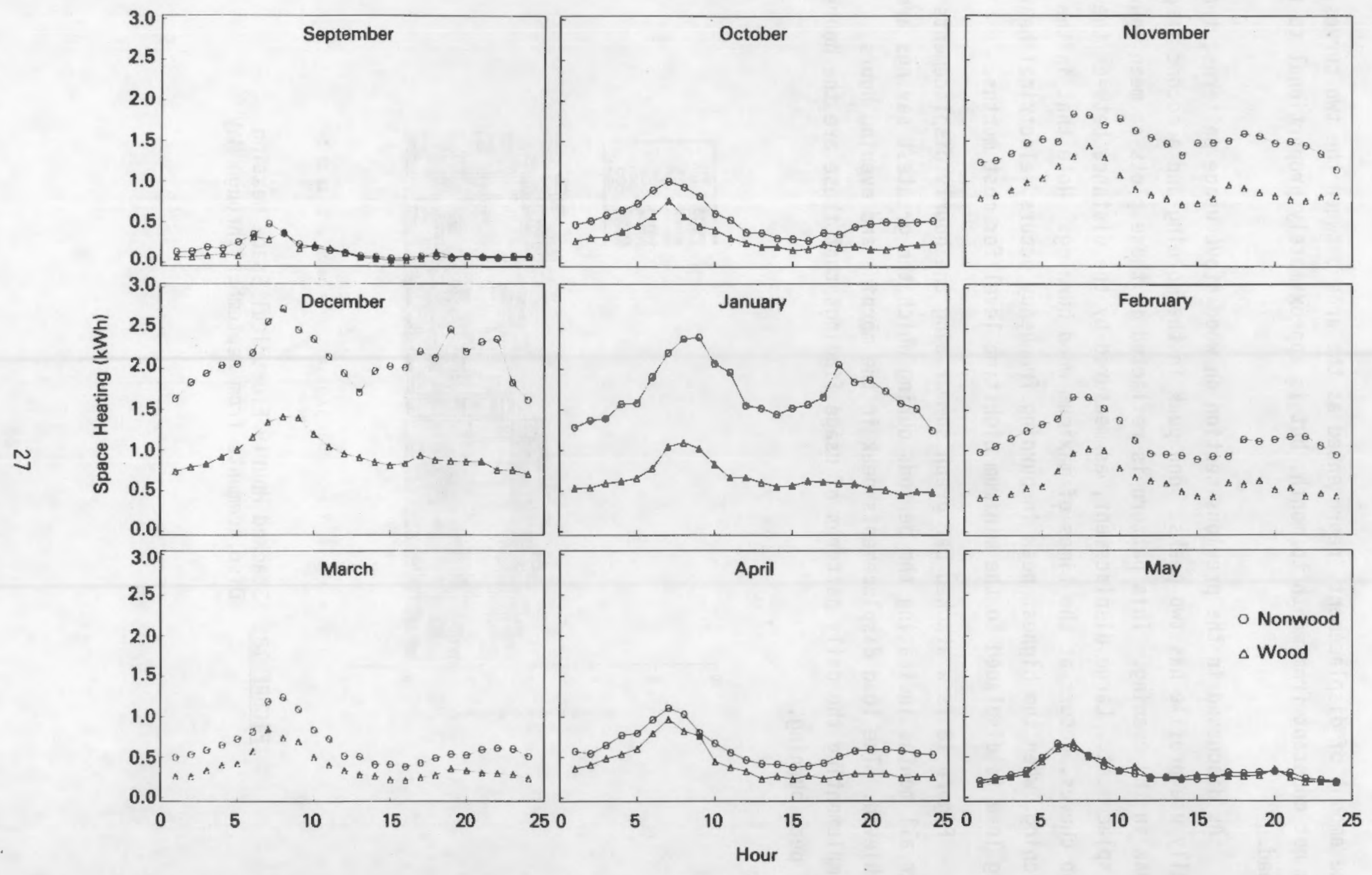

FIGURE 17. Mean Hourly Electrical Space Heating Load Profile for Nonwood-Use (0) and Wood-Use $(\Delta)$ Days from September Through May 
The amount of displacement, represented as the area between the two curves, is not constant from month to month, but is approximately proportional to the load.

As discussed in the previous section on wood stove usage patterns, the daily use profile has two peaks: one peak in the morning and a second larger peak in the evening. This pattern is reflected in these plots as mean hourly displacement. Large displacement, as measured by the distance between the two curves, occurs at the times of maximum wood burning. Note that in the evening, when the highest peak in burning frequency occurs, electrical heating load is displaced to the minimum nighttime level for most months.

Figure 18 is a stacked bar graph summarizing the hourly displacements for all months indicating the periods during which the greatest savings are achieved. The load displacements peak in the morning and evening hours, complementing the daily patterns of usage findings that these are the hours of peak burning.

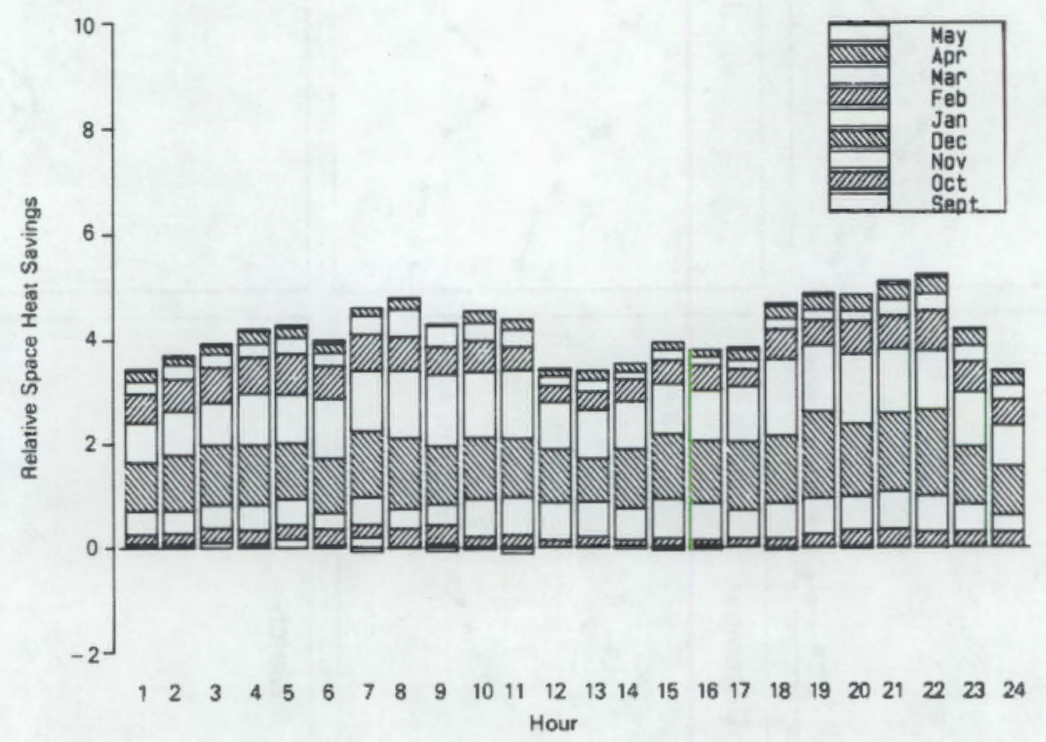

FIGURE 18. Stacked Hourly Electrical Space Heating Displacements from September Through May 
Because electrical utilities are concerned with the impact of wood stove use on power system efficiency, an examination of load factors was made based on the use of electrical space heating on wood-use and nonwood-use days. The load factor is calculated according to the equation:

$$
L F=\bar{x} / \text { xpeak }
$$

where LF is the load factor and $\bar{x}$ and xpeak are the mean and peak electrical space heating loads, respectively.

Table 3 shows the load factors derived from the peak monthly heating load relative to the mean load during the heating season for wood- and nonwood-use days across the sample. Comparison of the monthly load factors suggest that wood stove use significantly reduces the month-to-month variation in the load factor. This translates to a positive impact on the monthly grid system efficiencies.

In this discussion, the effect of wood heating on the electrical space heating load factor is based on comparisons of load factors for days when there is no wood burning to days when wood burning occurs daily. This is analogous to homes that either heat with wood daily or never heat with wood.

IABLE 3. The Mean Seasonal Heating Load (Wh), Monthly Peak Heating Load (Wh), and Associated Load Factor

\begin{tabular}{|c|c|c|c|c|}
\hline \multirow[b]{2}{*}{ Month } & \multicolumn{2}{|c|}{ Nonwood Use } & \multicolumn{2}{|c|}{ Wood Use } \\
\hline & Peak & Load Factor & Peak & Load Factor \\
\hline $\begin{array}{l}\text { Sep } \\
\text { Oct } \\
\text { Nov } \\
\text { Dec } \\
\text { Jan } \\
\text { Feb } \\
\text { Mar } \\
\text { Apr } \\
\text { May }\end{array}$ & $\begin{array}{r}479 \\
1006 \\
1832 \\
2738 \\
2387 \\
1657 \\
1243 \\
1108 \\
665\end{array}$ & $\begin{array}{l}2.0292 \\
0.9662 \\
0.5306 \\
0.3550 \\
0.4072 \\
0.5866 \\
0.7820 \\
0.8773 \\
1.4617\end{array}$ & $\begin{array}{r}371 \\
769 \\
1438 \\
1406 \\
1094 \\
1018 \\
847 \\
969 \\
680\end{array}$ & $\begin{array}{l}1.3989 \\
0.6749 \\
0.3609 \\
0.3691 \\
0.4744 \\
0.5098 \\
0.6128 \\
0.5356 \\
0.7632\end{array}$ \\
\hline $\begin{array}{l}\text { Mean } \\
\text { Seasona } 1\end{array}$ & 972 & & 519 & \\
\hline
\end{tabular}


The population of wood stove users in actuality provides some combination of both wood-use and nonwood-use days and ideally, the wood user load factor should be derived from this combination.

\subsection{SAMPLE DISPLACEMENT}

The aggregated heating values found in Tables 4 and 5 offer a method of calculating monthly and annual wood stove displacement for the sample. Because the sample is binned for wood-use and nonwood-use days, many of the structure-characteristic effects inherent in comparisons of samples composed of different sites can be ignored. Based on findings discussed earlier in

IABLE 4. Electrical Heating Values When No Wood Burning Occurred (Wh)

\begin{tabular}{|c|c|c|c|c|c|c|c|c|c|}
\hline Hour & Sep & Oct & Nov & $\mathrm{Dec} / 85$ & $\underline{\operatorname{Jan} / 86}$ & Feb & Mar & Apr & May \\
\hline $\begin{array}{c}1 \\
2 \\
3 \\
4 \\
5 \\
6 \\
7 \\
8 \\
9 \\
10 \\
11 \\
12 \\
13 \\
14 \\
15 \\
16 \\
17 \\
18 \\
19 \\
20 \\
21 \\
22 \\
23 \\
24\end{array}$ & $\begin{array}{r}131 \\
138 \\
192 \\
175 \\
255 \\
350 \\
479 \\
360 \\
226 \\
188 \\
150 \\
124 \\
85 \\
74 \\
58 \\
68 \\
83 \\
84 \\
65 \\
87 \\
72 \\
65 \\
85 \\
83 \\
\end{array}$ & $\begin{array}{r}469 \\
516 \\
588 \\
649 \\
730 \\
897 \\
1006 \\
932 \\
821 \\
606 \\
530 \\
377 \\
370 \\
304 \\
294 \\
276 \\
375 \\
354 \\
445 \\
485 \\
506 \\
500 \\
506 \\
522 \\
\end{array}$ & $\begin{array}{l}1233 \\
1254 \\
1338 \\
1471 \\
1518 \\
1486 \\
1832 \\
1815 \\
1695 \\
1778 \\
1625 \\
1539 \\
1464 \\
1317 \\
1476 \\
1476 \\
1499 \\
1591 \\
1557 \\
1467 \\
1490 \\
1439 \\
1338 \\
1138 \\
\end{array}$ & $\begin{array}{l}1630 \\
1830 \\
1941 \\
2040 \\
2054 \\
2192 \\
2577 \\
2738 \\
2473 \\
2363 \\
2145 \\
1942 \\
1705 \\
1972 \\
2030 \\
2013 \\
2214 \\
2132 \\
2489 \\
2209 \\
2328 \\
2367 \\
1829 \\
1616 \\
\end{array}$ & $\begin{array}{l}1279 \\
1367 \\
1390 \\
1569 \\
1576 \\
1901 \\
2194 \\
2369 \\
2387 \\
2067 \\
1956 \\
1549 \\
1515 \\
1436 \\
1516 \\
1558 \\
1651 \\
2052 \\
1835 \\
1865 \\
1724 \\
1573 \\
1510 \\
1240 \\
\end{array}$ & $\begin{array}{r}979 \\
1049 \\
1146 \\
1239 \\
1320 \\
1387 \\
1657 \\
1652 \\
1516 \\
1367 \\
1119 \\
956 \\
946 \\
932 \\
882 \\
922 \\
922 \\
1131 \\
1104 \\
1129 \\
1162 \\
1165 \\
1052 \\
936 \\
\end{array}$ & $\begin{array}{r}495 \\
533 \\
587 \\
650 \\
726 \\
814 \\
1189 \\
1243 \\
1094 \\
836 \\
725 \\
513 \\
508 \\
411 \\
412 \\
384 \\
428 \\
491 \\
540 \\
525 \\
596 \\
612 \\
602 \\
509 \\
\end{array}$ & $\begin{array}{r}570 \\
542 \\
648 \\
771 \\
794 \\
964 \\
1108 \\
1030 \\
799 \\
668 \\
552 \\
459 \\
413 \\
409 \\
371 \\
389 \\
424 \\
508 \\
574 \\
592 \\
595 \\
578 \\
546 \\
530\end{array}$ & $\begin{array}{l}2 \\
2 \\
2 \\
3 \\
2 \\
3 \\
3 \\
3 \\
2 \\
2 \\
1\end{array}$ \\
\hline Daily & 3675 & 13055 & 35837 & 50827 & 41077 & 27671 & 15422 & 14834 & 75 \\
\hline
\end{tabular}


IABLE 5. Electrical Heating Values when Wood Burning Was Used (Wh)

\begin{tabular}{|c|c|c|c|c|c|c|c|c|c|}
\hline Hour & Sep & Oct & Nov & $\mathrm{Dec} / 85$ & $\operatorname{Jan} / 86$ & Feb & Mar & Apr & May \\
\hline $\begin{array}{r}1 \\
2 \\
3 \\
4 \\
5 \\
6 \\
7 \\
8 \\
9 \\
10 \\
11 \\
12 \\
13 \\
14 \\
15 \\
16 \\
17 \\
18 \\
19 \\
20 \\
21 \\
22 \\
23 \\
24\end{array}$ & $\begin{array}{r}68 \\
70 \\
88 \\
106 \\
84 \\
317 \\
286 \\
371 \\
171 \\
218 \\
179 \\
118 \\
66 \\
52 \\
34 \\
33 \\
60 \\
136 \\
82 \\
84 \\
88 \\
79 \\
75 \\
74\end{array}$ & $\begin{array}{l}267 \\
311 \\
320 \\
385 \\
463 \\
581 \\
769 \\
575 \\
456 \\
402 \\
310 \\
245 \\
200 \\
200 \\
159 \\
171 \\
233 \\
195 \\
208 \\
172 \\
167 \\
204 \\
230 \\
236 \\
\end{array}$ & $\begin{array}{r}792 \\
823 \\
890 \\
988 \\
1038 \\
1186 \\
1308 \\
1438 \\
1296 \\
1078 \\
906 \\
835 \\
789 \\
716 \\
729 \\
791 \\
956 \\
918 \\
863 \\
823 \\
777 \\
761 \\
812 \\
827 \\
\end{array}$ & $\begin{array}{r}736 \\
792 \\
826 \\
916 \\
1002 \\
1160 \\
1342 \\
1406 \\
1396 \\
1196 \\
1041 \\
951 \\
905 \\
851 \\
810 \\
837 \\
935 \\
877 \\
864 \\
859 \\
859 \\
755 \\
751 \\
704 \\
\end{array}$ & $\begin{array}{r}535 \\
537 \\
596 \\
616 \\
656 \\
778 \\
1045 \\
1094 \\
1020 \\
826 \\
661 \\
662 \\
598 \\
548 \\
562 \\
618 \\
608 \\
589 \\
586 \\
524 \\
510 \\
446 \\
490 \\
480 \\
\end{array}$ & $\begin{array}{r}418 \\
429 \\
466 \\
534 \\
557 \\
749 \\
967 \\
1018 \\
998 \\
783 \\
671 \\
625 \\
591 \\
493 \\
432 \\
427 \\
598 \\
582 \\
625 \\
514 \\
535 \\
428 \\
465 \\
432 \\
\end{array}$ & $\begin{array}{l}267 \\
265 \\
338 \\
403 \\
420 \\
577 \\
847 \\
741 \\
697 \\
503 \\
408 \\
338 \\
290 \\
269 \\
222 \\
217 \\
251 \\
281 \\
360 \\
335 \\
308 \\
300 \\
289 \\
237 \\
\end{array}$ & $\begin{array}{l}358 \\
403 \\
485 \\
537 \\
602 \\
795 \\
969 \\
822 \\
761 \\
441 \\
369 \\
320 \\
227 \\
261 \\
224 \\
271 \\
230 \\
264 \\
295 \\
296 \\
297 \\
248 \\
258 \\
252\end{array}$ & $\begin{array}{l}171 \\
213 \\
250 \\
289 \\
442 \\
601 \\
680 \\
502 \\
455 \\
330 \\
376 \\
227 \\
243 \\
237 \\
270 \\
263 \\
255 \\
256 \\
268 \\
347 \\
241 \\
186 \\
188 \\
181 \\
\end{array}$ \\
\hline Dajly & 2937 & 7456 & 22340 & 22771 & 15584 & 14337 & 9165 & 9985 & 7470 \\
\hline
\end{tabular}

this report that there is no evidence that wood users in the different climate zones have different usage frequencies, estimates should be representative study wide.

The mean daily displacement for each month is calculated by differencing the hourly values for nonwood use (Table 4) and the hourly values for wood use (Table 5) and summing them. These differences and sums can be found in Table 6 and are represented graphically in Figure 18. These sums represent the mean displacement for those days of the month when the wood stove was actually used. To estimate the monthly savings, the mean number of days of wood use by month (Figure 7) must be factored in. The last 
TABLE 6. Electrical Space Heating Displaced by Wood Stove Use (Wh)

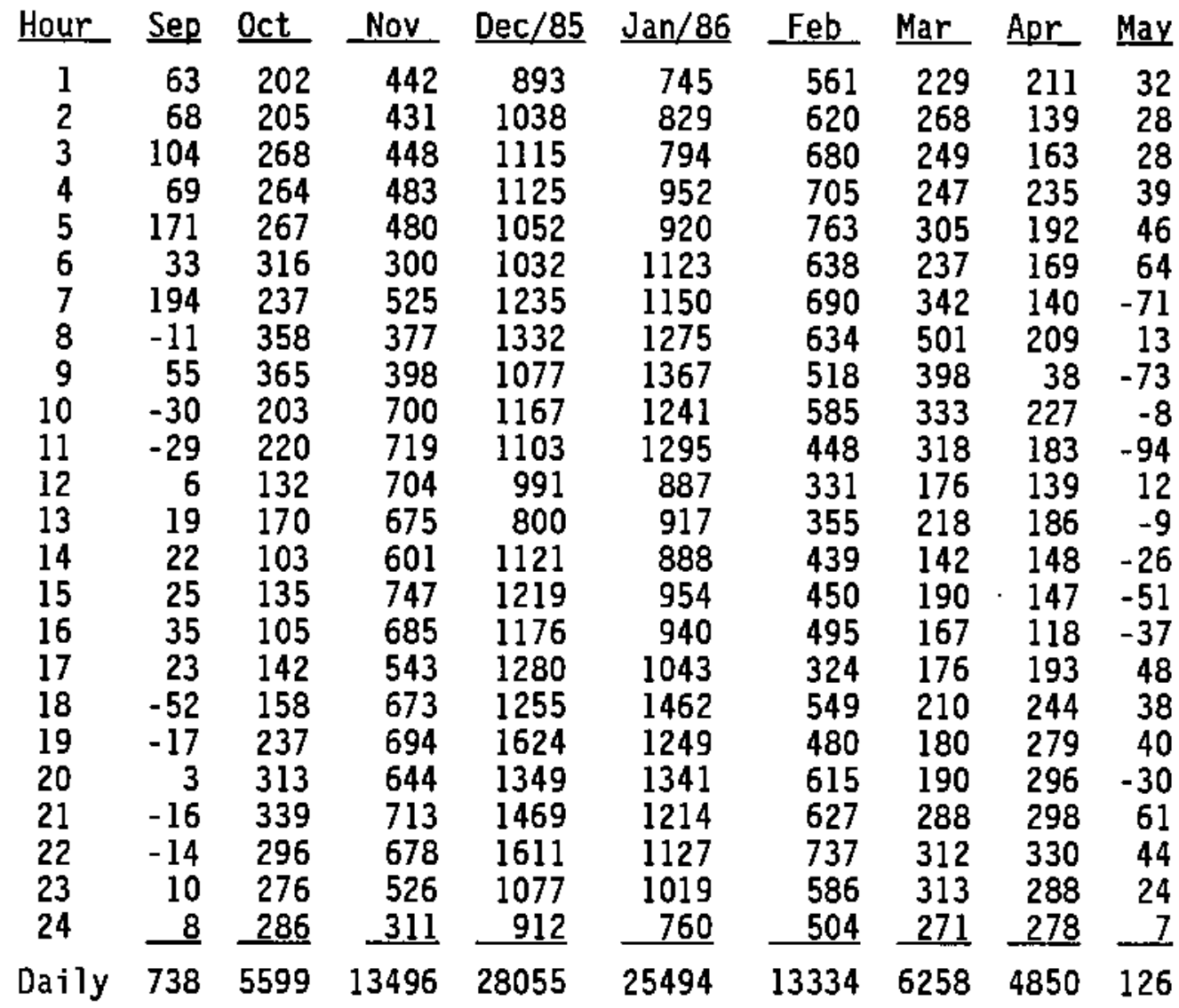

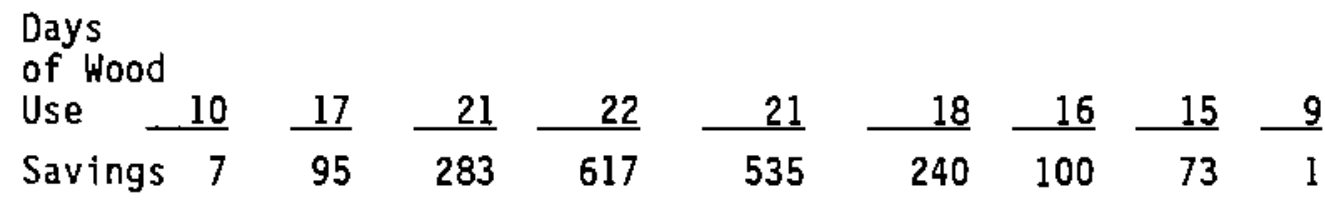

Annual Savings $1951 \mathrm{kWh}$

row of Table 6 gives the resulting estimate of mean monthly savings in kilowatt hours. Also listed is the mean annual savings for a wood burning site.

\subsection{ESTIMATE COMPARISONS}

In this study, wood stove displacement was calculated using two alternative methods; this allows a useful comparison. The load shape model estimated a mean annual savings of $1951 \mathrm{kWh}$ for residences heating with wood. 
This is $23 \%$ 1arger than the $1502-k$ Wh mean savings estimate derived from the two-parameter regression model. This difference can be explained by the limitation of the regression model; while providing a site-specific method for estimating displacement for light and moderate wood users, it is not accurate for sites with heavy wood use. Thus, an aggregate mean annual savings calculated from the resulting estimates would be biased toward low.

Estimates reported by other investigators of electrical heating load displacement by wood stove use in the Pacific Northwest are not common. One study, Residential Wood-Use in the Pacific Northwest: 1979-1985 (Tonn and White 1986), estimated very roughly that homes heated primarily with wood displaced about $6000 \mathrm{kWh}$ per year, or approximately $23 \%$ of their annual electricity demand. This estimate was derived through an examination of data from evaluations of Bonneville Power Administration (BPA) conservation programs to track differences between homes that were heated primarily with electricity or with wood. Considering that the study dealt with that portion of the wood burning population that burned wood the most heavily (those homes that use wood as the primary heating source), while the estimate presented here examined all those having the ability to heat with wood, their higher estimate is understandable.

In A Residential Conservation Data Base For the Pacific Northwest, Usibelli et al. (1983) made theoretical calculations of electrical space heating displacement by wood stoves. For these calculations, they assumed typical conversion energies for Northwest species of wood, numbers of cords burned, efficiencies of wood burning devices, and availability of wood burning devices. The result was that $1000 \mathrm{kWh} /$ year is displaced by wood burning in Climate Zones 1 and 2 and nearly $2000 \mathrm{kWh} /$ year is displaced in Climate Zone 3 . This displacement results in a 10 to $20 \%$ contribution to internal gains. These estimates appear to be somewhat low in comparison with ours considering that $85 \%$ of our sample falls into Climate Zones 1 and 2 .

The Bonneville Power Administration (BPA) predicted that by the year 2000 , wood burning could displace $4.6 \%$ of the electrical heating demand in the Pacific Northwest with an annual savings of $3720 \times 106 \mathrm{kWh}$ (Onisko 1980). 
This estimate was based on the assumption that $40 \%$ of the projected $1,943,700$ homes would burn wood. This equates to an average displacement of $4785 \mathrm{kWh}$ per residence burning some wood, which implies a combined increase of about 2.5 times in the wood stove penetration and intensity of use over the estimate presented here. Because the penetration is already $60 \%$ with the bulk of these sites burning at least $50 \%$ of the time in the ELCAP sample, the estimate of $4.6 \%$ displacement by the year 2000 may be somewhat high.

\subsection{CONCLUSIONS}

The examination of electrical space heating displacement by residential wood stove use can be summarized as follows:

- The envelope performance analysis used to assess conservation performance in the RSDP is strongly affected by wood stove use. Daily duration of wood burning is directly related to the amount of electrical space heating displaced.

- The two-parameter regression employed to model heating displacement for individual structures provided site-specific estimates but can only be applied to the light to moderate wood users. Thus, this method's resulting sample mean savings estimate of $1502 \mathrm{kWh} /$ year for the 1985/1986 heating season is correspondingly low.

- Daily electrical heating load shapes show an overall reduction throughout the heating season for days when there is wood heating. In particular, maximum displacement occurs during the morning and evening hours reflecting the periods when wood burning is heaviest (as established in the section on patterns of usage).

- The monthly electrical space heating displacement, as estimated from load shape examination, increases from the warmer months to the colder months (approximately in proportion to the heating load).

- Wood heating reduces the month to month variation in the power system load factor, as examined for nonwood-use and wood-use samples. 
- Estimates of electrical space heating displacement derived from differencing aggregate load profiles for wood use and nonwood use provide reasonable sample values. Homes that burned wood in this study displaced an average of $1951 \mathrm{kWh}$ of electrical space heating during the 1985/1986 heating season. 


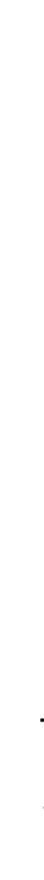




\subsection{REFERENCES}

Bonneville Power Administration. 1985. Procedures Manual for ELCAP Residential Building Characteristics Survey. DOE/BPA-1379-9, Bonneville Power Administration, Portland, Oregon.

Fels, M. F., and D. 0. Stram. 1986. "The Effects of Burning Wood on Saving Electricity." Energy and Buildings. 9:119-126.

Hadley, D. L., and R. M. Pincus. 1985. "Pacific Northwest Climatology." In Workshop II Abstracts, End-Use Load and Conservation Assessment Program. DOE/BPA/13795-10, Bonneville Power Administration, Portland, Oregon.

Lane Regional Air Pollution Authority. 1984. 1984 Home Heating Survey Summary. Lane Regional Air Pollution Authority, Springfield, Oregon.

Modera, M. P. 1985. "Monitoring the Heat Output of a Wood Stove." Energy and Buildings. $8: 79-80$.

Modera, M. P., and R. C. Sonderegger. 1980. Determination of In-Site Performance of Fireplaces. LBL-10701, Lawrence Berkeley Laboratory, Berkeley, Cal ifornia.

Northwest Power Planning Council (NWPPC). 1986. Northwest Conservation and Electric Power Plan. NWPPC, Public Involvement Division, Portland, Oregon.

Onisko, S. A. 1980. Biomass End-Use Resource Report. Bonneville Power Administration, Port land, Oregon.

Oregon Department of Environmental Quality. 1985. Portland Area Wood Heating Survey 1985. Oregon Department of Environmental Qualjty, Air Quality Division, Portland, Oregon.

Schuster, G. J., and S. D. Tomich, 1985. ELCAP: Description of Field Data Acquisition System for Building Enerqy Monitoring. DOE/BPA-13795-4, Bonneville Power Administration, Portland, Oregon.

Sheldon, J. W. 1983. Solid Fuels Encyclopedia. Garden Way Publishing, Charlotte, Vermont.

Skog, K. E., and I. A. Watterson. 1983. Residential Fuelwood Use in the United States: 1980-1981. U.S. Department of Agriculture, Forest Service, Forest Products Laboratory, Madison, Wisconsin.

Stokes, R. A., and E. W. Pearson. 1985. "ELCAP RSDP Data a Representative Envelope Performance Analysis." In Workshop II Abstracts, End-Use Load and Conservation Assessment Program. DOE/BPA/13795-10, Bonneville Power Administration, Portiand, Oregon. 
Tonn, B., and D. White. 1986. Residential Wood-Use in the Pacific Northwest: 1979-1985. ORNL/CON-216, Oak Ridge Nationa1 Laboratory, Oak Ridge, Tennessee.

Usibelli, A., B. Gardner, W. Luhrsen, and A. Mejer. 1983. A Residential Conservation Data Base For The Pacific Northwest. LBL-18107, Lawrence Berkeley Laboratory, Berkeley, California. 
APPENDIX A

DISTRIBUTION OF DATA 
APPENDIX A

\section{DISTRIBUTION OF DATA}

TABLE A.1. Number of Days When the Wood Stove Was Used

Site/Year SEP OCT NOV DEC JAN FEB MAR APR MAY

$\begin{array}{rrrrrrrrrr}002685 & 2 & 5 & 11 & 11 & 5 & 3 & 2 & 0 & 0 \\ 003085 & 0 & 0 & 10 & 25 & 30 & 17 & 29 & 27 & 16 \\ 003185 & 24 & 21 & 30 & 30 & 22 & 27 & 28 & 30 & 18 \\ 003385 & 0 & 0 & 0 & 0 & 0 & 15 & 16 & 6 & 10 \\ 004485 & 0 & 0 & 0 & 0 & 0 & 0 & 0 & 0 & 0 \\ 005085 & 0 & 0 & 0 & 0 & 0 & 0 & 0 & 0 & 1 \\ 005585 & 0 & 0 & 17 & 28 & 27 & 16 & 16 & 17 & 9 \\ 006185 & 0 & 8 & 27 & 29 & 26 & 8 & 27 & 18 & 12 \\ 006685 & 3 & 23 & 25 & 27 & 31 & 21 & 27 & 24 & 21 \\ 006785 & 0 & 0 & 0 & 0 & 0 & 0 & 0 & 0 & 0 \\ 006885 & 0 & 0 & 0 & 0 & 0 & 0 & 0 & 0 & 0 \\ 006985 & 0 & 16 & 22 & 30 & 20 & 23 & 18 & 14 & 3 \\ 007285 & 0 & 0 & 0 & 0 & 0 & 0 & 0 & 5 & 11 \\ 007585 & 18 & 15 & 0 & 0 & 0 & 0 & 0 & 0 & 0 \\ 008585 & 0 & 0 & 23 & 22 & 15 & 22 & 3 & 1 & 3 \\ 011985 & 0 & 0 & 0 & 0 & 0 & 0 & 0 & 0 & 0 \\ 012585 & 0 & 0 & 12 & 24 & 19 & 18 & 2 & 2 & 4 \\ 012885 & 21 & 9 & 0 & 0 & 0 & 0 & 0 & 0 & 0 \\ 012985 & 0 & 0 & 0 & 0 & 6 & 26 & 30 & 8 & 0 \\ 013485 & 0 & 0 & 0 & 0 & 0 & 0 & 7 & 26 & 22 \\ 013685 & 9 & 27 & 11 & 16 & 28 & 17 & 24 & 26 & 18 \\ 013885 & 0 & 0 & 21 & 27 & 28 & 0 & 0 & 0 & 0 \\ 014485 & 10 & 28 & 16 & 23 & 22 & 16 & 24 & 19 & 21 \\ 014785 & 9 & 19 & 29 & 27 & 31 & 16 & 0 & 5 & 25 \\ 016385 & 0 & 0 & 0 & 20 & 0 & 0 & 5 & 20 & 3 \\ 016585 & 2 & 3 & 14 & 31 & 30 & 27 & 28 & 23 & 19 \\ 017785 & 0 & 15 & 30 & 29 & 23 & 14 & 0 & 4 & 0 \\ 018085 & 16 & 25 & 19 & 24 & 31 & 20 & 28 & 27 & 9 \\ 018685 & 0 & 1 & 0 & 0 & 0 & 0 & 0 & 0 & 0 \\ 020385 & 0 & 0 & 12 & 30 & 11 & 28 & 29 & 17 & 13 \\ 020485 & 0 & 0 & 0 & 0 & 0 & 21 & 23 & 21 & 13 \\ 021185 & 7 & 6 & 10 & 16 & 10 & 3 & 0 & 8 & 4 \\ 021685 & 0 & 1 & 15 & 28 & 20 & 1 & 0 & 0 & 0 \\ 022385 & 0 & 0 & 0 & 0 & 0 & 0 & 0 & 0 & 0 \\ 022485 & 6 & 22 & 29 & 21 & 26 & 21 & 26 & 27 & 12 \\ 022785 & 0 & 1 & 10 & 20 & 0 & 0 & 0 & 0 & 0 \\ 023785 & 0 & 0 & 0 & 0 & 0 & 4 & 3 & 8 & 4 \\ 023985 & 0 & 0 & 0 & 3 & 1 & 4 & 0 & 0 & 0 \\ 024385 & 16 & 20 & 6 & 18 & 14 & 24 & 18 & 17 & 14 \\ 024585 & 1 & 21 & 5 & 28 & 24 & 10 & 0 & 2 & 0\end{array}$


TABLE A.1. (contd)

Site/Year SEP OCT $\underline{\text { NOV DEC JAN FEB MAR APR MAY }}$

$\begin{array}{rrrrrrrrrr}024685 & 2 & 2 & 10 & 30 & 31 & 23 & 24 & 27 & 12 \\ 024985 & 0 & 10 & 22 & 29 & 27 & 27 & 23 & 22 & 12 \\ 025685 & 0 & 0 & 0 & 0 & 0 & 0 & 0 & 0 & 0 \\ 025985 & 1 & 25 & 28 & 30 & 13 & 0 & 0 & 4 & 3 \\ 026185 & 29 & 31 & 29 & 30 & 31 & 25 & 25 & 28 & 17 \\ 026285 & 0 & 0 & 0 & 4 & 0 & 0 & 1 & 1 & 2 \\ 027185 & 0 & 0 & 21 & 31 & 30 & 26 & 27 & 22 & 13 \\ 027685 & 0 & 0 & 12 & 19 & 29 & 23 & 22 & 20 & 11 \\ 03785 & 0 & 0 & 0 & 19 & 30 & 27 & 30 & 24 & 14 \\ 034385 & 0 & 21 & 29 & 30 & 31 & 22 & 8 & 5 & 1 \\ 034785 & 10 & 11 & 8 & 4 & 4 & 12 & 12 & 5 & 0 \\ 035085 & 0 & 3 & 3 & 0 & 0 & 0 & 0 & 0 & 0 \\ 035185 & 0 & 5 & 21 & 26 & 17 & 18 & 1 & 0 & 0 \\ 035285 & 0 & 8 & 7 & 9 & 3 & 4 & 0 & 4 & 5 \\ 035785 & 24 & 25 & 23 & 24 & 28 & 27 & 21 & 19 & 17 \\ 036385 & 3 & 18 & 27 & 29 & 30 & 27 & 22 & 11 & 11 \\ 036585 & 0 & 0 & 0 & 0 & 0 & 0 & 0 & 0 & 0 \\ 036985 & 19 & 20 & 27 & 22 & 29 & 27 & 20 & 13 & 14 \\ 037185 & 1 & 26 & 16 & 28 & 29 & 28 & 21 & 25 & 5 \\ 037485 & 1 & 26 & 28 & 20 & 0 & 0 & 25 & 12 & 12 \\ 037685 & 15 & 25 & 3 & 25 & 18 & 12 & 0 & 1 & 0 \\ 033985 & 9 & 28 & 27 & 31 & 31 & 27 & 26 & 25 & 14 \\ 038085 & 0 & 20 & 29 & 30 & 30 & 28 & 21 & 6 & 3 \\ 038285 & 0 & 0 & 0 & 0 & 0 & 0 & 0 & 14 & 18 \\ 038485 & 2 & 3 & 16 & 7 & 1 & 0 & 2 & 11 & 2 \\ 039285 & 0 & 9 & 26 & 30 & 30 & 24 & 24 & 1 & 4 \\ 039585 & 0 & 1 & 21 & 25 & 31 & 26 & 9 & 0 & 0 \\ 039985 & 11 & 28 & 25 & 23 & 26 & 25 & 2 & 8 & 10 \\ 040085 & 0 & 6 & 10 & 16 & 12 & 6 & 2 & 3 & 6 \\ 040685 & 7 & 15 & 27 & 29 & 31 & 23 & 16 & 16 & 7 \\ 041885 & 16 & 30 & 15 & 18 & 1 & 1 & 3 & 21 & 22 \\ 042585 & 0 & 0 & 0 & 0 & 0 & 0 & 0 & 6 & 12 \\ 042985 & 0 & 0 & 0 & 0 & 0 & 0 & 0 & 1 & 0 \\ 043385 & 0 & 0 & 0 & 0 & 0 & 0 & 0 & 3 & 11 \\ 043485 & 0 & 0 & 0 & 0 & 0 & 6 & 7 & 0 & 2 \\ 043585 & 1 & 27 & 29 & 28 & 13 & 26 & 24 & 25 & 18 \\ 043685 & 0 & 0 & 10 & 11 & 15 & 11 & 3 & 6 & 4 \\ 043885 & 0 & 0 & 0 & 0 & 6 & 26 & 25 & 29 & 18 \\ 046185 & 0 & 0 & 2 & 9 & 0 & 0 & 0 & 0 & 0 \\ 046285 & 3 & 22 & 12 & 11 & 12 & 9 & 8 & 5 & 6 \\ 046385 & 2 & 29 & 30 & 30 & 29 & 25 & 27 & 21 & 13 \\ 046585 & 0 & 0 & 0 & 0 & 0 & 0 & 0 & 0 & 0 \\ 046885 & 0 & 0 & 0 & 20 & 15 & 25 & 26 & 29 & 11 \\ 046985 & 0 & 8 & 21 & 0 & 14 & 19 & 14 & 12 & 5 \\ 0447855 & 0 & 0 & 0 & 0 & 0 & 0 & 0 & 0 & 0 \\ 047385 & 4 & 19 & 25 & 23 & 26 & 16 & 16 & 15 & 12 \\ 048985 & 0 & 0 & 0 & 0 & 0 & 0 & 0 & 16 & 12 \\ 049085 & 0 & 0 & 0 & 0 & 0 & 0 & 16 & 28 & 17 \\ 049185 & 0 & 0 & 12 & 4 & 2 & 0 & 0 & 0 & 0\end{array}$


TABLE A.1. (contd)

Site/Year SEP OCT NOV DEC JAN FEB MAR APR MAY

$\begin{array}{rrrrrrrrrr}049385 & 0 & 0 & 0 & 0 & 2 & 21 & 0 & 0 & 0 \\ 049685 & 0 & 0 & 0 & 0 & 2 & 11 & 7 & 4 & 0 \\ 050785 & 0 & 4 & 23 & 29 & 12 & 15 & 30 & 29 & 6 \\ 051285 & 0 & 0 & 0 & 0 & 0 & 0 & 0 & 0 & 3 \\ 051385 & 0 & 0 & 17 & 1 & 0 & 0 & 0 & 0 & 0 \\ 051485 & 0 & 0 & 11 & 29 & 31 & 27 & 28 & 23 & 4\end{array}$

IABLE A.2. Number of Days When the Wood Stove Was Not Used

Site/Year SEP OCT NOV DEC JAN FEB MAR APR MAY

$\begin{array}{rrrrrrrrrr}002685 & 28 & 24 & 16 & 10 & 26 & 23 & 25 & 30 & 30 \\ 003085 & 0 & 0 & 0 & 0 & 0 & 0 & 2 & 2 & 6 \\ 003185 & 4 & 3 & 0 & 0 & 0 & 0 & 0 & 0 & 8 \\ 003385 & 0 & 0 & 0 & 0 & 0 & 0 & 6 & 4 & 16 \\ 004485 & 22 & 16 & 30 & 28 & 25 & 26 & 31 & 25 & 26 \\ 005085 & 0 & 0 & 0 & 0 & 0 & 4 & 27 & 29 & 28 \\ 005585 & 0 & 0 & 1 & 1 & 4 & 11 & 15 & 12 & 21 \\ 006185 & 0 & 0 & 0 & 0 & 0 & 0 & 0 & 0 & 10 \\ 006685 & 6 & 0 & 3 & 1 & 0 & 4 & 2 & 4 & 10 \\ 006785 & 0 & 0 & 0 & 0 & 0 & 0 & 0 & 0 & 0 \\ 006885 & 0 & 8 & 15 & 29 & 19 & 27 & 14 & 6 & 22 \\ 006985 & 0 & 6 & 3 & 0 & 0 & 3 & 11 & 16 & 26 \\ 007285 & 0 & 0 & 0 & 0 & 0 & 0 & 0 & 0 & 7 \\ 007585 & 1 & 0 & 0 & 0 & 0 & 0 & 0 & 0 & 0 \\ 008585 & 0 & 5 & 7 & 3 & 5 & 4 & 10 & 17 & 21 \\ 011985 & 0 & 15 & 30 & 30 & 17 & 0 & 0 & 0 & 0 \\ 012585 & 0 & 0 & 7 & 0 & 0 & 6 & 29 & 24 & 27 \\ 012885 & 9 & 1 & 0 & 0 & 0 & 0 & 0 & 0 & 0 \\ 012985 & 0 & 0 & 0 & 0 & 0 & 0 & 1 & 9 & 0 \\ 013485 & 0 & 0 & 0 & 0 & 0 & 0 & 2 & 0 & 2 \\ 013685 & 7 & 2 & 1 & 0 & 0 & 1 & 4 & 3 & 12 \\ 013885 & 0 & 8 & 3 & 0 & 2 & 28 & 19 & 18 & 28 \\ 014485 & 0 & 2 & 0 & 0 & 0 & 0 & 0 & 0 & 5 \\ 014785 & 18 & 12 & 1 & 0 & 0 & 12 & 28 & 11 & 5 \\ 016385 & 4 & 0 & 0 & 0 & 0 & 0 & 8 & 9 & 28 \\ 016585 & 14 & 28 & 14 & 0 & 0 & 0 & 2 & 4 & 10 \\ 017785 & 25 & 16 & 0 & 0 & 7 & 14 & 29 & 26 & 29 \\ 018085 & 5 & 5 & 0 & 0 & 0 & 0 & 0 & 2 & 11 \\ 018685 & 20 & 28 & 29 & 31 & 29 & 28 & 31 & 28 & 30 \\ 020385 & 0 & 0 & 0 & 1 & 17 & 0 & 0 & 13 & 0 \\ 020485 & 0 & 0 & 0 & 0 & 0 & 3 & 8 & 8 & 18 \\ 021185 & 23 & 24 & 20 & 15 & 20 & 23 & 30 & 21 & 24 \\ 021685 & 30 & 30 & 15 & 3 & 11 & 26 & 31 & 30 & 30 \\ 022385 & 0 & 0 & 0 & 0 & 0 & 0 & 0 & 0 & 0\end{array}$


TABLE A.2. (contd)

Site/Year SEP OCT NOV DEC JAN EEB MAR APR MAY

$\begin{array}{rrrrrrrrrr}022485 & 14 & 0 & 1 & 0 & 1 & 5 & 5 & 2 & 17 \\ 022785 & 0 & 0 & 0 & 0 & 0 & 0 & 26 & 20 & 27 \\ 023785 & 0 & 0 & 0 & 0 & 0 & 20 & 26 & 21 & 26 \\ 023985 & 0 & 0 & 0 & 16 & 29 & 23 & 31 & 29 & 29 \\ 024385 & 14 & 7 & 3 & 1 & 2 & 2 & 11 & 10 & 16 \\ 024585 & 27 & 10 & 1 & 0 & 6 & 18 & 17 & 19 & 31 \\ 024685 & 8 & 0 & 0 & 0 & 0 & 3 & 6 & 1 & 11 \\ 024985 & 0 & 1 & 0 & 0 & 1 & 1 & 7 & 7 & 18 \\ 025685 & 19 & 0 & 0 & 0 & 0 & 0 & 0 & 0 & 0 \\ 025985 & 26 & 4 & 0 & 0 & 18 & 18 & 0 & 2 & 27 \\ 026855 & 1 & 0 & 0 & 0 & 0 & 3 & 6 & 2 & 13 \\ 026285 & 0 & 0 & 0 & 21 & 25 & 24 & 28 & 28 & 28 \\ 027185 & 0 & 0 & 0 & 0 & 0 & 1 & 2 & 8 & 11 \\ 027685 & 20 & 30 & 2 & 0 & 0 & 1 & 7 & 8 & 19 \\ 031785 & 0 & 0 & 0 & 0 & 0 & 0 & 1 & 5 & 16 \\ 034385 & 14 & 7 & 0 & 0 & 0 & 0 & 8 & 24 & 14 \\ 034785 & 17 & 18 & 8 & 25 & 1 & 15 & 17 & 15 & 3 \\ 035085 & 29 & 25 & 25 & 30 & 31 & 20 & 27 & 25 & 28 \\ 035185 & 19 & 25 & 5 & 5 & 12 & 10 & 23 & 1 & 0 \\ 035285 & 2 & 14 & 21 & 18 & 25 & 23 & 31 & 25 & 26 \\ 035785 & 1 & 3 & 0 & 0 & 0 & 0 & 1 & 10 & 13 \\ 036385 & 25 & 10 & 1 & 0 & 0 & 1 & 6 & 14 & 18 \\ 036585 & 0 & 0 & 0 & 0 & 0 & 0 & 16 & 29 & 25 \\ 03695 & 7 & 10 & 1 & 0 & 2 & 0 & 6 & 12 & 11 \\ 037185 & 0 & 0 & 0 & 0 & 0 & 0 & 2 & 0 & 2 \\ 037485 & 20 & 0 & 0 & 0 & 0 & 0 & 0 & 8 & 14 \\ 037685 & 13 & 5 & 19 & 6 & 11 & 16 & 26 & 21 & 30 \\ 037985 & 0 & 0 & 0 & 0 & 0 & 0 & 0 & 0 & 16 \\ 038085 & 10 & 9 & 0 & 0 & 0 & 0 & 5 & 17 & 16 \\ 038285 & 0 & 0 & 0 & 0 & 0 & 0 & 0 & 0 & 10 \\ 038485 & 26 & 25 & 13 & 23 & 30 & 26 & 25 & 17 & 28 \\ 039285 & 30 & 20 & 1 & 0 & 1 & 1 & 6 & 28 & 26 \\ 039585 & 30 & 28 & 9 & 0 & 0 & 1 & 16 & 23 & 24 \\ 039985 & 13 & 2 & 1 & 0 & 4 & 3 & 1 & 5 & 20 \\ 04085 & 4 & 23 & 19 & 15 & 18 & 22 & 28 & 22 & 25 \\ 040685 & 12 & 14 & 3 & 1 & 0 & 3 & 14 & 14 & 23 \\ 041885 & 14 & 1 & 0 & 0 & 0 & 0 & 0 & 7 & 9 \\ 042585 & 0 & 0 & 0 & 0 & 0 & 0 & 0 & 0 & 18 \\ 042985 & 0 & 0 & 0 & 0 & 0 & 0 & 0 & 11 & 30 \\ 043385 & 0 & 0 & 0 & 0 & 0 & 0 & 0 & 0 & 0 \\ 043485 & 0 & 0 & 0 & 0 & 5 & 19 & 12 & 3 & 26 \\ 043585 & 5 & 0 & 0 & 0 & 0 & 0 & 1 & 3 & 9 \\ 043685 & 0 & 0 & 11 & 18 & 13 & 15 & 26 & 21 & 26 \\ 043885 & 0 & 0 & 0 & 0 & 0 & 0 & 5 & 0 & 0 \\ 046185 & 0 & 2 & 16 & 21 & 19 & 27 & 31 & 29 & 27 \\ 046285 & 3 & 9 & 17 & 18 & 18 & 18 & 23 & 25 & 24 \\ 046385 & 4 & 2 & 0 & 1 & 1 & 2 & 4 & 9 & 17 \\ 046585 & 5 & 29 & 30 & 29 & 31 & 26 & 27 & 29 & 31 \\ 046885 & 0 & 0 & 0 & 0 & 0 & 2 & 0 & 0 & 9\end{array}$


IABLE A.2. (contd)

Site/Year SEP OCT NOV DEC JAN FEB MAR APR MAY

$\begin{array}{llllllllll}046985 & 5 & 21 & 1 & 0 & 4 & 8 & 16 & 17 & 24\end{array}$

$\begin{array}{llllllllll}047285 & 5 & 29 & 28 & 29 & 30 & 28 & 29 & 28 & 30\end{array}$

$\begin{array}{rrrrrrrrrr}047385 & 2 & 11 & 1 & 1 & 5 & 9 & 15 & 15 & 18 \\ 048985 & 0 & 0 & 0 & 0 & 0 & 0 & 0 & 4 & 17\end{array}$

$\begin{array}{llllllllll}049085 & 0 & 0 & 0 & 0 & 0 & 0 & 2 & 1 & 13\end{array}$

$\begin{array}{llllllllll}049185 & 0 & 0 & 15 & 26 & 28 & 27 & 30 & 30 & 30\end{array}$

$\begin{array}{llllllllll}049385 & 0 & 0 & 0 & 0 & 0 & 1 & 0 & 4 & 30\end{array}$

$\begin{array}{llllllllll}049685 & 0 & 0 & 0 & 0 & 0 & 17 & 20 & 24 & 30\end{array}$

$\begin{array}{llllllllll}050785 & 0 & 0 & 0 & 0 & 0 & 0 & 0 & 0 & 25\end{array}$

$\begin{array}{llllllllll}051285 & 0 & 0 & 0 & 0 & 0 & 0 & 0 & 0 & 24\end{array}$

$\begin{array}{rrrrrrrrrr}051385 & 0 & 0 & 1 & 14 & 22 & 28 & 29 & 19 & 29 \\ 051485 & 0 & 0 & 0 & 1 & 0 & 0 & 2 & 7 & 25\end{array}$ 
PNL -6713

UC $-95 c$

\section{DISTRIBUTION}

No. of

Copjes

OFFSITE

10 DOE/Office of Scientific and Technical Information

R. A. Gillman

Bonneville Power Administration

P.0. Box 362l-RPEE

Portland, OR 97208-3621

2 F. J. Peterson

Bonnevitle Power Administration

P.0. Box 3621-RPEE

Portland, OR 97208-3621

S. G. Hauser

Battelle Portland office

500 N.E. Multnomah

Suite 650

Portland, OR 97232
No, of

Copies

ONSITE

DOE Richland Operations Office

E.C. Norman

17 Pacific Northwest Laboratory

J. W. Falco

J. M. Hales

P. C. Hays

E. W. Kleckner

B. A. LeBaron (2)

R. G. Pratt

W. F. Sandusky

J. A. Stottlemyre

M. E. Strong

R. E. Wildung

Publishing Coordination

Technical Report Files (5) 
